\title{
Factor Price Equalization in a Dynamic Economy
}

Joseph E. Stiglitz

Cowles Foundation, Yale University

Two of the most important propositions of the modern theory of international trade are extensions of the Heckscher-Ohlin analysis of comparative advantage: Free international trade completely equalizes factor prices (and thus ensures world Pareto optimality), and the removal of protective barriers decreases the return of the scarce factor in terms of both commodities and increases that of the abundant factor. ${ }^{1}$ Both of these propositions were proved under seemingly general conditions, although in the context of a static model.

But whether these results still hold in a dynamic economy has, almost without exception, gone uninvestigated in the literature. ${ }^{2}$ In a dynamic model, moreover, there is the additional question of whether international trade, even if it equalized rental rates on machines, would equalize rates of interest, in particular if the two countries had different rates of time preference. Recently, Samuelson (1965) showed that if there is nonspecialization (and the other assumptions of the Samuelson-HeckscherOhlin model are satisfied), then interest rates as well as rental rates are equalized.

It has long been recognized, however, that if factor supplies are variable, specialization is much more likely to occur. Indeed, one of the principal reasons Ohlin (1933) did not argue for complete factor price equalization

The research described in this paper was carried out under grants from the National Science Foundation and the Ford Foundation and was completed while at the Institute for Development Studies, University College, Nairobi, under a grant from the Rockefeller Foundation. I wish to thank D. Cass, R. Cooper, and the referee for helpful discussions and comments.

${ }^{1}$ See Stolper and Samuelson (1941) and Samuelson (1948, 1949, 1953-54). The crucial assumptions are: $(a)$ endowment ratios are not separated by one or more factor intensity reversals, and $(b)$ both countries remain incompletely specialized. (In addition, of course, the two countries must have identical constant returns to scale production functions.) For a thorough discussion of these assumptions, see Johnson (1958).

${ }^{2}$ See Inada (1968). Other articles investigating dynamic international trade models include those of Bardhan (1965, 1966), Kenen (1965), and Oniki and Uzawa (1965). 
but only for a "tendency" for equalization was his concern about elastic factor supplies: "There can be little doubt that as a rule supply reactions tend to offset the price-equalizing tendencies of trade" (p. 124). He argued that, as the return to the abundant factor increases, its supply (relative to the supply of the other factor) increases. ${ }^{3}$ Thus, in the long run, free international trade tends to increase the disparity in factor supplies between the two countries, and if this increase is sufficient will result in specialization and nonequalization of factor prices. Indeed, Ohlin went so far as to suggest that "trade means specialization" (p. 125).

The purpose of this paper is to investigate in detail the long-run supply responses of capital and their implications for the classical propositions. We focus on the behavior of a two-country model in which the long-run rate of interest in each country is fixed, for example, by the pure rate of time preference in the case of "rational" savings behavior, or by the savings behavior of capitalists if workers save nothing. In this case, unless the two countries have identical long-run interest rates, at least one of the two countries must specialize. For in long-run equilibrium, nonspecialization at a common price ratio implies the same rate of interest as well as the same wage-rentals ratio. The world price ratio may be that of one or the other country, or something in between if both specialize. In the unspecialized country, factor prices are unchanged, but the relative scale of the two industries will vary as a result of trade. In the specialized country, the relative price of imports is below the autarky (no-trade) price.

If imports of the specialized country are capital goods, the capital-labor ratio in the remaining consumption-goods industry must rise to restore the old rate of interest, thereby raising the wage-rentals ratio as well as wages in terms of both goods. Whether this makes factor price differentials between the two countries larger or smaller depends on whether the consumption-goods exporter's wage-rental ratio is larger or smaller than the capital-goods exporter's wage-rental ratio, and this in turn depends on whether the consumption-goods sector is more or less capital-intensive than the capital-goods sector. Thus, free trade, in the case of the normal capital intensity hypothesis, increases factor price differentials and (in the specialized country) increases the return of the relatively scarce factor (labor) in terms of both commodities, as well as relative to the returns to capital. Since the capital-labor ratio in each sector in the unspecialized country is unchanged, whether its aggregate capital-labor ratio goes up or down depends on whether it exports the capital-intensive or the laborintensive commodity. On the other hand, whether the (specialized) consumption-goods exporter increases or decreases his capital-labor ratio depends not only on whether consumption is capital- or labor-intensive but also on the extent to which the price of consumption after trade is greater than that before trade, for the higher price of consumption goods raises profits (the return to capital). If the consumption-goods sector is

${ }^{3}$ See also Walsh (1956), Vanek (1959), and Caves (1960). 
capital-intensive, the Ohlin proposition that trade increases factor supply differentials is valid, but if it is labor-intensive, it may not be.

On the other hand, if only one of the two countries specializes and it exports capital goods, since the interest rates are unchanged, the capitallabor ratio in the capital goods industry (the only remaining one) is unchanged and the wage-rentals ratio is unchanged. Thus factor price ratio differentials after trade are identical with those before trade. But while in the unspecialized country both factors have the same factor prices in terms of both commodities, in the specialized capital-goods exporting country, both factors are better off in terms of consumption goods, since its relative price has fallen (as compared with the autarky situation). Since in each industry the free-trade equilibrium capital-labor ratio is identical with the pre-trade capital-labor ratio, the country with the lower rate of interest and the higher aggregate capital-labor ratio (and which will export the capital-intensive commodity) will increase its capital-labor ratio, and conversely for the high interest rate economy, so factor supply differentials are always increased in this case.

After setting up the basic model in Section I, and analyzing the pre-trade equilibrium in Section II, we investigate the long-run free-trade equilibrium in Section III. In Section IV, we show that, because the high interest rate (high time preference) country is willing to trade future consumption for present consumption with the low interest rate country, it always has a lower long-run consumption with free trade than pre-trade, and conversely for the low interest rate economy. In Section $\mathrm{V}$, the patterns of specialization are investigated. Section VI considers the effects of trade policy on the long-run equilibrium; it is shown that a tariff (export subsidy) may lead to a higher consumption per capita in both countries. The reason for this is simple: Assume, for instance, that the exporter of consumption goods is specialized, the importer unspecialized. The exporter, by imposing, for example, an export subsidy, raises the domestic price of consumption goods above the foreign. Since the rate of interest is fixed, this leads to an increase in the capital-labor ratio, and to an increase in consumption per capita. The increased demand for capital goods leads the capital goods exporter to shift resources to that sector, which leads, if it is the capital-intensive sector, to an increase in its aggregate capital-labor ratio and per capita consumption.

Section VII considers some extensions of the analysis. In the Appendix, the nature of the dynamic path is analyzed.

\section{The Basic Model}

\section{A. Technology}

As usual, we assume that the production functions have constant returns to scale, are identical in both countries, and satisfy the usual assumptions of 
concavity and differentiability:

$$
\begin{aligned}
& C=C\left(K_{c}, L c\right)=L_{c} C\left(K_{c} / L_{c}, 1\right)=L_{c} c\left(k_{c}\right), \\
& Z=Z\left(K_{z}, L_{z}\right)=L_{z} Z\left(K_{z} / L_{z}, 1\right)=L_{z} z\left(k_{z}\right),
\end{aligned}
$$

where $C$ is the output of consumption goods, $Z$ that of capital goods, $K_{c}$ and $L_{c}$ the capital and labor used in the consumption-goods sector, and $k_{c}$ their ratio; similarly for capital goods. One of the sectors is assumed to be more capital-intensive than the other; that is, at every factor price ratio, ${ }^{4}$ the capital-labor ratio in one sector is greater than that in the other. The aggregate capital-labor ratio we shall denote by $k=K / L$.

\section{B. Prices of Factors and Commodities}

The economy is assumed to be competitive, so each factor is paid its marginal product. Thus

$r=\max \left[p c^{\prime}\left(k_{c}\right), z^{\prime}\left(k_{z}\right)\right] ; \quad w=\max \left\{p\left[c-k_{c} c^{\prime}\left(k_{c}\right)\right], z-k_{z} z^{\prime}\left(k_{z}\right)\right\}$,

where $r$ is the rental rate on machines, $w$ the wage rate, and $p$ the price of consumption goods in terms of capital, which, if there is no specialization, is ${ }^{5} z^{\prime}\left(k_{z}\right) / c^{\prime}\left(k_{c}\right)$. If specialization occurs, then the price will be determined to make the value of exports equal to the value of imports.

\section{Labor Supply}

Labor is assumed to be growing at the same, constant rate, $n$, in both countries, so that the ratio of their labor supplies is fixed, $L^{B} / L^{A}=a$. The assumption of identical growth rates is, of course, necessary for the existence of a balanced growth path in which one country is not infinitesimal relative to the other. ${ }^{6}$

\section{Sarings}

In most of the analysis of this paper, we will consider two alternative hypotheses about savings. First, rational savings: We assume that the aggregative savings behavior of our economy may be described by the

${ }^{4}$ The assumption of no factor intensity reversals is, of course, crucial in the proof of the factor price equalization theorem (see Johnson 1958). To ensure the existence of an equilibrium, we shall also assume that both production functions satisfy the Inada conditions.

${ }^{5}$ As usual, if there is no specialization, the wage-rentals ratio uniquely determines the capital intensity in each sector and relative prices. As the wage-rentals ratio increases, the price of the good which is intensive in labor increases relative to the price of the other good.

${ }^{6}$ That is, if one of the countries is growing more slowly than the other, it will eventually become infinitesimal in relation to the other. This is subsumed in the special case of $a=0$ or infinity. 
behavior of a representative consumer who chooses his savings rate at each moment of time so as to maximize his intertemporal utility. ${ }^{7}$ For most of the analysis, we employ the conventional assumption that the utility function is of the form ${ }^{8}$

$$
W=\int_{0}^{\infty} U[c(t)] e^{-(\delta-n)} d t, \quad \delta>n,
$$

where $\delta$ is the pure rate of time preference. ${ }^{9}$ Utility maximization requires that the marginal rate of substitution equal the marginal rate of transformation, or

$$
-\frac{d \ln U^{\prime}(c)}{d t}+\delta=r
$$

Thus, in steady state,

$$
r=\delta .
$$

Although the technologies of the two economies are identical, there is no reason to assume that they have identical tastes; neither $\delta$ nor $U(c)$ need be the same for the two.

Second, Marxian savings: In the Marxian model, a constant fraction of profits, $s$, is saved, and none of wages (see Uzawa 1961). Then

$$
\frac{\dot{k}}{k}=s r-n,
$$

or, in steady state,

$$
r=\frac{n}{s}
$$

If we set $\delta=n / s$, the long-run behavior is identical for the two models.

It should be emphasized, however, that although the long-run implications of these two savings assumptions are identical, the short-run dynamics are quite different (see Appendix).

In the following discussion, we shall denote with a superscript $A$ the country with the higher rate of time preference (the lower savings rate), and by a superscript $B$ the other country. ${ }^{10}$

${ }^{7}$ For other studies employing this approach in other contexts, see Uzawa (1968a, 1968b).

${ }^{8}$ Later, we consider an alternative form of the utility function.

${ }^{9}$ We weight utility of per capita consumption by the size of the population; alternatively, we may think of $\delta-n$ as the "net rate" at which future utility is discounted. From the individual's viewpoint, the rate of return on capital equals rentals plus expected capital gains. In long-run equilibrium, however, capital gains are zero, so we still obtain equation (5).

${ }^{10}$ Throughout the discussion, we assume $\delta^{A} \neq \delta^{B}\left(s^{A} \neq s^{B}\right)$. If $\delta^{A}=\delta^{B}\left(s^{A}=s^{B}\right)$, pre-trade prices are identical in the two countries; even when the possibility of trade opens up, no trade will in fact take place. 


\section{Before Trade (Comparative Dynamics)}

We assume that before trade opens up, each country is in steady state (balanced growth). From equation (5) or (7), the rate of return on capital is uniquely determined. Hence, the capital-labor ratio in both industries, the wage-rentals ratio, and relative prices are all uniquely determined. The country with the higher $\delta$ (or lower savings propensity) has the higher rate of return on capital and thus the lower $k_{z}$; hence both its wage-rentals ratio and the value of $k_{c}$ are lower. Moreover, straightforward calculations verify that the country with the higher rate of pure time preference has the smaller capital-labor ratio. ${ }^{11}$ If the consumption-goods sector is capital(labor-) intensive, then its relative price, $p$, is higher (lower) in the country with the higher $\delta$ (see fig. 1).

\section{The Opening of Trade}

Now trade opens up between the two countries. There are two cases to consider.

\section{A. Consumption-Goods Sector Is Capital-intensive: $\mathrm{k}_{\mathrm{z}}<\mathrm{k}_{\mathrm{c}}$}

Since the price of consumption goods is higher in the country with the higher rate of pure time preference, that country imports consumption goods and exports capital goods. In the short run the price will be somewhere in between the before-trade prices, and accordingly, in the short run, whether the countries specialize or not, factor price differentials between the two countries are reduced. But note what happens now: In the Marxian interpretation of our model, profits in the high savings country are increased, those in the low savings country are reduced. Before trade opened in both countries, capital grew at the same rate as labor. Now, in the high savings country, capital is growing faster so the capital-labor ratio increases; and conversely in the low savings country. Similarly, in the intertemporal utility maximization interpretation of the model, in the country with low $\delta, \delta$ now is less than $r$. This induces an increase in savings in the low $\delta$ country; conversely in the other economy.

${ }^{11}$ In balanced growth,

where

$$
n k=\rho z\left(k_{z}\right)
$$

$$
\rho=L_{z} / L=\left(k-k_{c}\right) /\left(k_{z}-k_{c}\right),
$$

so

$$
\begin{aligned}
\frac{d k}{d \delta} & =\frac{\left[(\partial \rho / \partial \delta) z+\rho z^{\prime}\left(\partial k_{z} / \partial \delta\right)\right]}{[n-(\partial \rho / \partial k) z]} \\
& =\left\{z(1-\rho) \frac{\partial k_{c}}{\partial \delta}+\rho\left[\left(z-k_{z} z^{\prime}\right)+z^{\prime} k_{c}\right] \frac{\partial k_{z}}{\partial \delta}\right\} / \frac{n k_{c}}{\rho}<0
\end{aligned}
$$




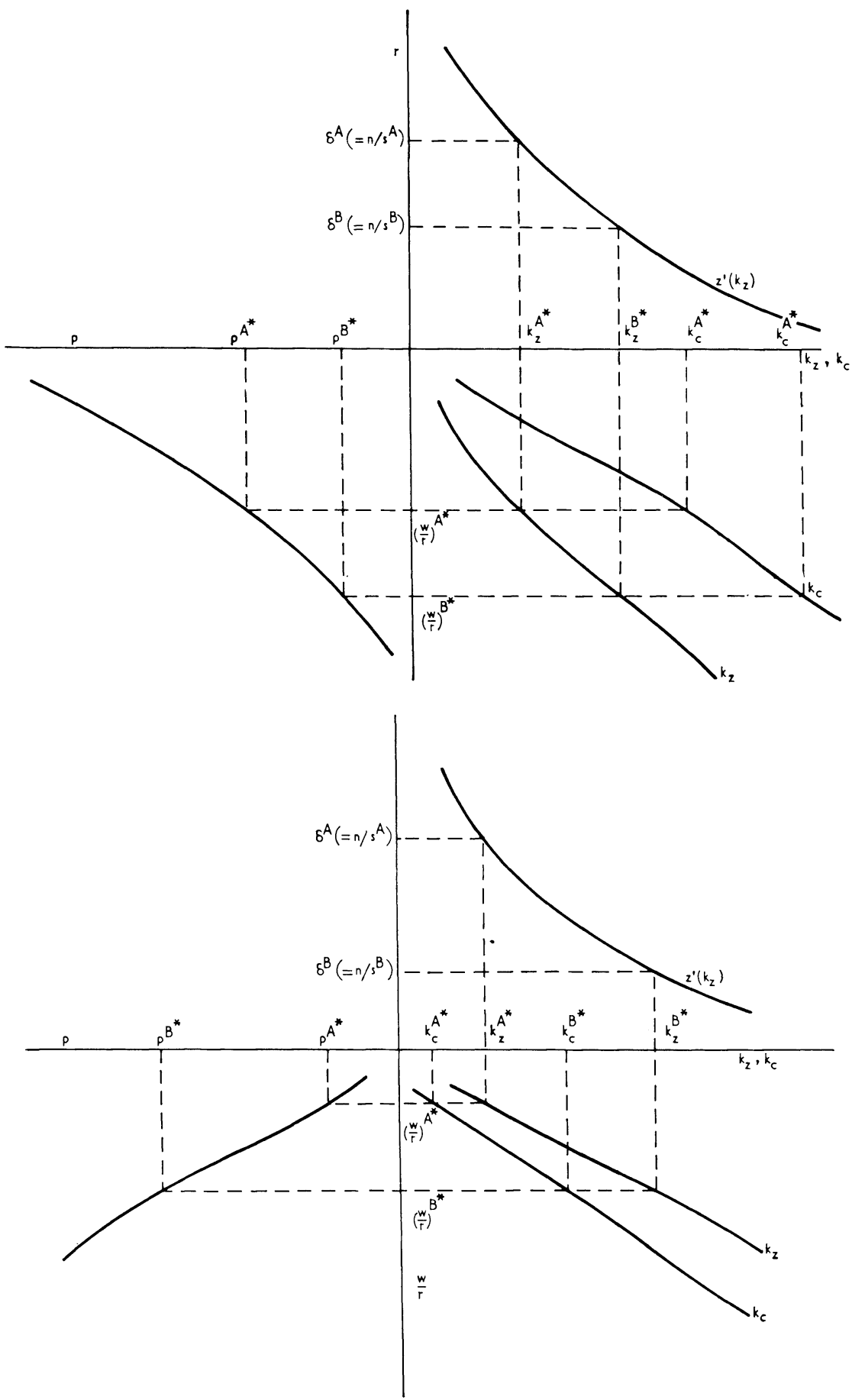

FIG. 1.-Determination of pre-trade long-run equilibrium: top, $k_{c}>k_{z}$; bottom, $k_{c}<k_{z}$. 
What does the world look like when the countries are once again in long-run equilibrium? First, we have already observed that at least one of the countries must specialize. For, as we have already established, in longrun equilibrium, we have, as before the opening of trade, $r$ in $A$ equal to $\delta^{A}\left(=n / s^{A}\right)$ and in $B$ equal to $\delta^{B}\left(=n / s^{B}\right)$. If both did not specialize, the two different rates of return would imply different wage-rentals ratios and different price ratios. But prices, in free trade, must be the same in both countries.

Second, since specialization must occur, factor prices are not equalized. In fact, interest rate differentials remain at exactly their pre-trade level. But, not only are factor price differentials not eliminated, they may actually increase. To see this, consider first what happens to $A$.

Since the country with the higher rate of time preference (the lower savings rate) has a lower pre-trade price of capital goods relative to consumption goods, it will produce and export investment goods. The "capital-poor" economy exports capital goods. Thus, $r$, which is just equal to the marginal product of capital in the investment-goods industry, in longrun equilibrium must be equal to $\delta^{A}\left(=n / s^{A}\right)$. The country with the higher rate of pure time preference (lower savings rate) in long-run equilibrium has exactly the same capital-labor ratio in the investment-goods industry as before trade opened up, and the same wage-rentals ratio.

Now consider what happens in $B$. If $B$ (high $s$ or low $\delta$ ) specializes, the long-run international price of consumption goods, $\hat{p}$, must be greater than its pre-trade price, $p^{B *}$ :

$$
\delta^{B}\left(=n / s^{B}\right)=p^{B *} c^{\prime}\left(k_{c}^{B *}\right)<\hat{p} c^{\prime}\left(k_{c}^{B *}\right) .
$$

But long-run equilibrium requires

$$
\delta^{B}\left(=n / s^{B}\right)=r^{B}=\hat{p} c^{\prime}\left(\hat{k}_{c}^{B}\right),
$$

where carets denote values of the variables in long-run free-trade equilibrium and asterisks denote those in pre-trade equilibrium. Since $c^{\prime \prime}<0$, $\hat{k}_{c}^{B}>k_{c}^{B *}$, which means that the wage-rentals ratio has increased. Since before trade the wage-rentals ratio in the second country $(B)$ was larger than in the first $(A)$, the discrepancy has increased. If, on the other hand, $B$ does not specialize, $\hat{p}=p^{B *}$, so $k_{c}^{B *}=\hat{k}_{c}^{B}$, the wage-rentals ratio is unchanged. Thus the country with the lower rate of time preference in long-run equilibrium has a higher (unchanged) capital-labor ratio in the consumption-goods sector than before trade opens up, and a higher (unchanged) wage-rentals ratio if it specializes (does not specialize). Factor price differentials are increased or unchanged as B specializes or does not specialize. Note that in this model, long-run comparative adtantage is determined completely by preferences (sacings rates) and has nothing to do with initial endowments of capital and labor. ${ }^{12}$

${ }^{12}$ If our initial situation is the long-run autarky equilibrium, the country with the initially higher capital-labor ratio will also have a higher wage-rentals ratio and will, 
Moreover, it is possible that the return to no factor in terms of either commodity may decrease, and the return to the factor which before trade is relatively scarce may increase relative to the returns to the abundant factor. If $B$ does not specialize, returns to both of its factors in terms of both commodities are identical with their pre-trade values. In $A$, returns to both factors in terms of capital are unchanged, but in terms of consumption goods which are now cheaper, both factors are unambiguously better off. If both countries specialize (or $A$ does not), in $A$ returns to both factors in terms of capital are unchanged; in terms of consumption goods, which are now cheaper (or unchanged), returns to both factors are increased (or unchanged). In $B$ (high savings), the return to labor in terms of consumption goods is increased, since $k_{c}^{B}$ has increased, ${ }^{13}$ and, since the relative price of capital goods has decreased, the return to labor in terms of capital goods is increased. On the other hand, since the rate of interest is fixed, the return to capital goods in terms of capital goods is unchanged, and since the relative price of consumption goods has increased, the return to capital in terms of consumption goods has decreased.

Note that in this case the Ohlin proposition that factor supply differentials are increased is true. The capital-labor ratio of $A$ is reduced, since the aggregate capital-labor ratio is simply a linear combination of that for each sector, and the capital-goods sector is the less capital-intensive sector. Since $A$ exports capital goods, the capital intensity in each sector after trade is the same as before trade, but a larger proportion (possibly all) of the labor force is now allocated to the investment-goods sector ${ }^{14}$ Similarly, the capital-labor ratio in $B$ is increased. Consider the case where $B$ specializes: We have already observed $\hat{k}^{B}>k_{c}^{B *}$, but $k^{B *}<k_{c}^{B *}$, so $\hat{k}^{B}>k^{B *}$. If $B$ does not specialize, the capital intensities in each sector are unchanged, but since $B$ exports consumption goods a larger proportion of the labor force is allocated to the capital-intensive sector, so the aggregate capitallabor ratio must increase.

\section{B. The Capital-Goods Sector Is More Capital-intensive: $\mathrm{k}_{\mathrm{z}}>\mathrm{k}_{\mathrm{c}}$}

The analysis for this case follows essentially along the lines of the previous case, with the following important modifications.

in long-run equilibrium, export the capital-intensive good. But for arbitrary initial conditions, which country has the comparative advantage in a given commodity may change in the process of growth (see the Appendix). Ohlin (1933) and ValavanisVail (1954) have also argued that for long-run comparative advantage, producible factors of production are irrelevant.

${ }^{13}$ The ratio of returns to labor in terms of capital goods after and before trade is $\hat{p}\left[c\left(\hat{k}_{c}^{B}\right)-\hat{k}_{c}^{B} c^{\prime}\left(\hat{k}_{c}^{B}\right)\right] / p^{*}\left[c\left(k_{c}^{B *}\right)-k_{c}^{B *} c^{\prime}\left(k_{c}^{B *}\right)\right]$ $=\left\{\left[c\left(\hat{k}_{c}^{B}\right)-\hat{k}_{c}^{B} c^{\prime}\left(\hat{k}_{c}^{B}\right)\right] /\left[c^{\prime}\left(\hat{k}_{c}^{B}\right)\right]\right\} /\left\{\left[c\left(k_{c}^{B *}\right)-k_{c}^{B *} c^{\prime}\left(k_{c}^{B *}\right)\right] /\left[c^{\prime}\left(k_{c}^{B *}\right)\right]\right\}>1$.

${ }^{14}$ Since $k=\rho k+(1-\rho) k_{c}$ (where $\rho$ is defined in $\left.n .11\right)$, if $\rho$ increases, $k_{z}$ and $k_{c}$ being held constant, $k$ must decrease. (See below, n. 18, for a detailed proof of these results.) 
1. The consumption-goods exporter is now the high time preference (low savings rate) economy; the capital-goods exporter is the low time preference (high savings rate) economy.

2. The wage-rentals ratio in the high time preference (low savings rate) country increases while that in the other is unchanged, so factor price differentials are reduced, but never eliminated. But it is still true that it is possible that no factor will be worse off in terms of either commodity as a result of the opening of trade.

3. The Ohlin proposition that factor supply differentials are increased may no longer be true if $A$ (the high time preference, low savings rate country) specializes. Although it specializes in the labor-intensive sector (which has the effect of reducing $k$ ), the favorable terms of trade (low price of capital goods relative to consumption goods) may raise income, profits, and the return on capital sufficiently to more than offset the first effect, and hence $k^{A}$ may increase. If, for instance, the country with the high rate of time preference $(A)$ is infinitesimal in size relative to the other country, then the other country's capital-labor ratio is changed infinitesimally; $A$, however, specializes in producing consumption goods, and since $\delta^{A}=p^{B *} c^{\prime}\left(\hat{k}^{A}\right)$, if $p^{B *}$ is sufficiently larger than $p^{4 *}, \hat{k}^{A}>k^{A *}$. Since $\hat{k}^{B}=k^{B *}, \hat{k}^{B}-\hat{k}^{A}<k^{B *}-k^{A *}$.

\section{Social Welfare and Changes in Long-Run Consumption Per Capita}

We shall now show that the opening of free trade may result in a lowering of long-run consumption per capita. First, we consider the special case of a small country in a large world, so that the country has no effect on international prices. In figure 2 we have plotted the before (dotted line) and after (solid line) relationship between long-run consumption per capita and the rate of interest. ${ }^{15}$ Since in the long run, $r$ is equal to the pure rate of time preference (or in the Marxian model, to $n / s$ ), we can immediately

${ }^{15}$ The before-trade curve is derived as usual: $k_{z}=z^{\prime-1}(r)=k_{z}(r), k_{z}^{\prime}(r)<0$. Before trade, there cannot be specialization, so $k_{\mathrm{c}}$ is uniquely determined by $k_{z}$ and is monotonic; $k_{c}=k_{c}(r), k_{c}^{\prime}(r)<0$. Balanced growth without trade implies $\left\{\left[k-k_{c}(r)\right] /\left[k_{z}(r)-k_{c}(r)\right] ; z\left[k_{z}(r)\right]=n k\right.$, which can be solved for $k(r)$. Then $c=$ $\left[k(r)-k_{z}(r)\right] /\left[k_{c}(r)-k_{z}(r)\right] c\left[k_{c}(r)\right]=c(r)$. Straightforward calculation shows that $c(r)$ attains a maximum at $r=n$, the golden rule, and is monotonic on either side of $r=n$. The after-trade curve is derived as follows: Denote by $\tilde{r}$ the equilibrium rental rate in the large country. Then if $k_{z}<k_{c}$, and if $r<\tilde{r}$, the small country specializes in consumption goods, and $c(r)=c[k(r)]-n k(r)$ where $k(r)=c^{-1}(r / \hat{p})$. If $r>\tilde{r}$, the small country specializes in capital goods, so $c(r)=\{z[k(r)]-n k(r)]: / \hat{p}$ where $k(r)=$ $z^{\prime-1}(r)$. If $r=\tilde{r}$, then long-run consumption per capita depends on the allocation of the labor force between the two sectors: $c(r)=\left\{\rho z\left(k_{z}\right)+(1-\rho) \hat{p} c\left(k_{c}\right)-n\left[\rho k_{z}+\right.\right.$ $\left.(1-\rho) k_{\mathrm{c}}\right] / / \hat{p}$, where $\rho=\left(k-k_{c}\right) /\left(k_{z}-k_{c}\right)$ and where $k_{\mathrm{c}}$ and $k_{z}$ are determined by $\tilde{r}$. Then $d c / d \rho=\left[z-\hat{p} c-n\left(k_{z}-k_{c}\right)\right] / \hat{p}=\left[\left(k_{z}-k_{c}\right)(\tilde{r}-n)\right] / \hat{p}<0$ if $k_{z}<k_{c}$, $\tilde{r}>n$. For one value of $\rho$, the small country neither exports nor imports: $c$ has exactly the same value as before trade. Similarly for $k_{z}<k_{c}$, except now for $r<\tilde{r}$, the small country exports capital goods and for $r>\tilde{r}$, it imports capital goods. 


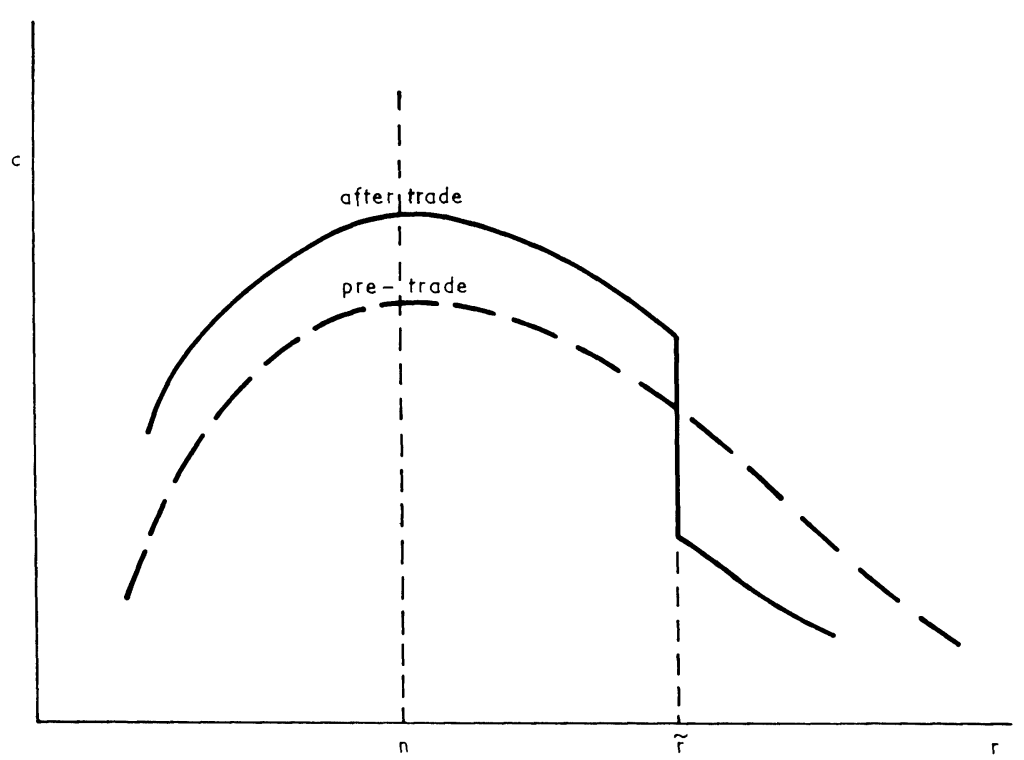

FIG. 2.-Consumption per capita pre-trade and after trade

determine the equilibrium per capita consumption. Note that if the rate of time preference in the small country is larger than in the "rest of the world" per capita consumption falls, while if the opposite is true it rises. Should we, therefore, conclude that the opening of trade may have lowered social welfare? Obviously not. The opening of trade has unambiguously increased the consumption possibility set of the economy (if $r \neq \tilde{r}$ ), and therefore the country is unambiguously better off. What has happened is that the opening of trade has changed the pattern of consumption over time, and more consumption may be taken earlier (if the country has a higher rate of time preference than the rest of the world). This provides another example of the fallacy of looking at long-run (steady-state) consumption per capita to measure welfare.

More generally, since the long-run equilibrium values of $r$ after trade are the same as before trade, the country with the high rate of time preference has an equilibrium consumption per capita lower after trade than before, and conversely for the other country, independent of assumptions about capital intensity.

The results of this and the preceding section are summarized in table 1.

\section{Long-Run Patterns of Specialization}

Many of the results discussed in the previous section depended on the pattern of specialization. For the given technology, this depends on rates of time 


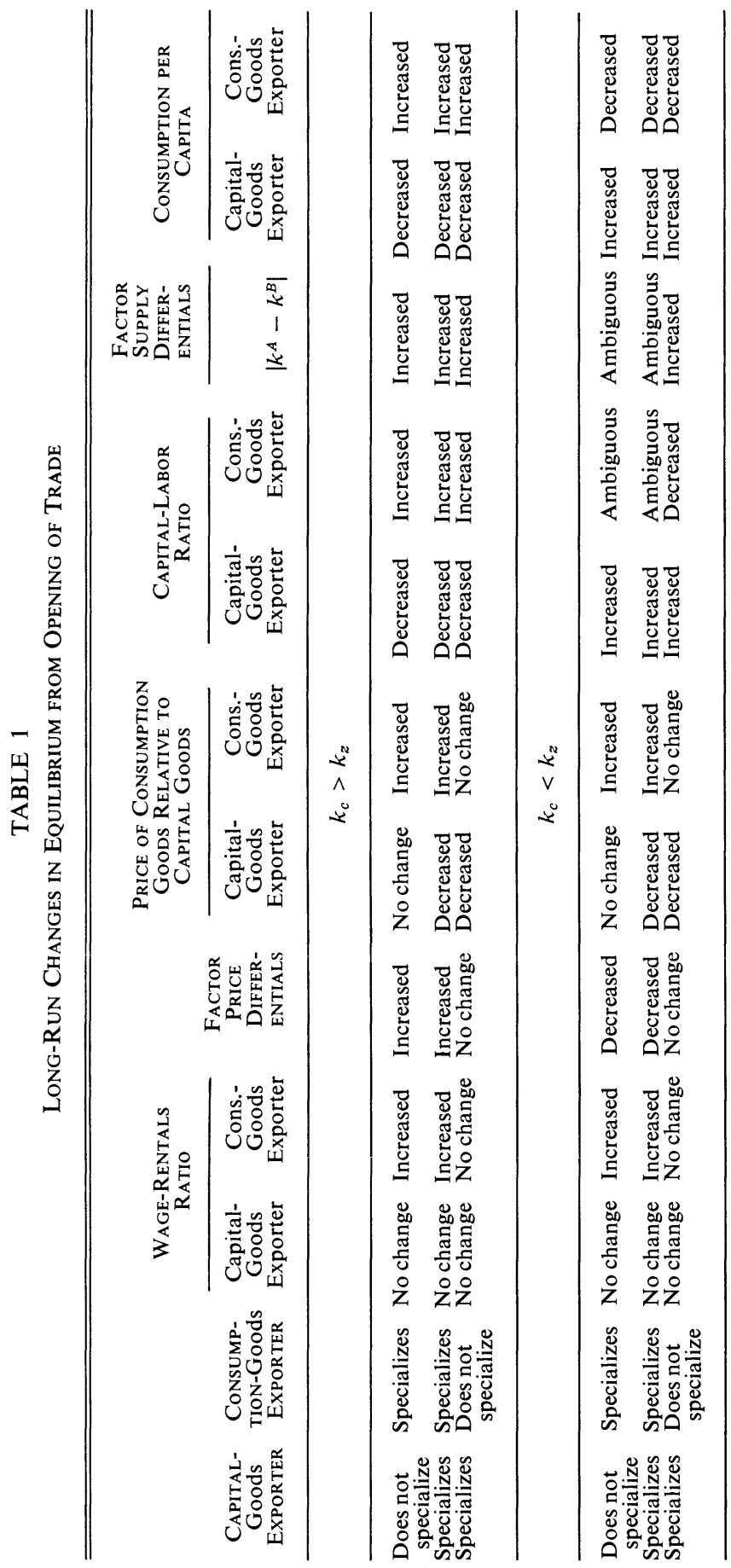


preference (savings behavior) as well as the relative sizes of the two economies. In this section we briefly investigate the patterns of specialization.

We begin by deriving the long-run excess demand curves for, say, capital goods, $D(\hat{p})$, in each country (in per capita terms). It will have three regions: If the price of capital goods relative to consumption goods is very low, the country specializes in consumption goods, and hence demands capital goods; conversely if the relative price of capital goods is very high. Only at $\hat{p}=p^{i *}$ can the country not specialize. More precisely, the demand curve is given by

$$
D^{i}(\hat{p})= \begin{cases}n c^{\prime-1}\left(\delta^{i} / \hat{p}\right) & \hat{p}>p^{i *} \\ {\left[n c^{\prime-1}\left(\delta^{i} / p^{i *}\right), z\left[z^{\prime-1}\left(\delta^{i}\right)\right]-n z^{\prime-1}\left(\delta^{i}\right)\right]} & \hat{p}=p^{i *} \\ z\left[z^{\prime-1}\left(\delta^{i}\right)\right]-n z^{\prime-1}\left(\delta^{i}\right) & \hat{p}<p^{i *} .\end{cases}
$$

International equilibrium requires $L^{A} D^{A}=-L^{B} D^{B}$, or, since $L^{B} / L^{A}=a$,

$$
D^{A}(\hat{p})=-a D^{B}(\hat{p}) .
$$

That a solution exists is guaranteed by the continuity of the demand functions; indeed, from what we have already shown, it is clear that the solution $\hat{p}$ is such that $p^{A *} \geq \hat{p} \geq p^{B *}$ (if $k_{c}>k_{z}$; if $k_{c}<k_{z}$, reverse the inequalities). The three possible patterns of specialization are given by figure 3 for $k_{c}>k_{z} \cdot{ }^{16}$

The equilibrium values for $\hat{k}^{A}, \hat{k}^{B}, \hat{p}$, and $D^{A}$ in the three situations are then given by table $2 .{ }^{17}$

TABLE 2

Determination of Long-Run Equilibrium Values for Alternative Patterns of

\begin{tabular}{|c|c|c|}
\hline $\begin{array}{l}\text { Country } A \text { Specializes, } \\
\text { Country } B \text { Does Not }\end{array}$ & $\begin{array}{l}\text { Both } \\
\text { Specialize }\end{array}$ & $\begin{array}{l}\text { Country } B \text { Specializes, } \\
\text { Country } A \text { Does Not }\end{array}$ \\
\hline $\begin{array}{l}\hat{p}=p^{B *} \\
D^{A}=z\left(\hat{k}^{A}\right)-n \hat{k}^{A} \\
\hat{k}^{A}=k_{z}^{A *}=z^{\prime-1}\left(\delta^{A}\right) \\
\hat{k}^{B}=\frac{D^{A} / a-z\left(k_{z}^{B *}\right) / \hat{k}_{c}^{B}\left(\hat{k}_{z}^{B}-\hat{k}_{c}^{B}\right)}{n-z\left(\hat{k}_{z}^{B}\right) /\left(\hat{k}_{z}^{B}-\hat{k}_{c}^{B}\right)} \\
\hat{k}_{z}^{B}=k_{z}^{B *}=z^{\prime-1}\left(\delta^{B}\right) \\
\hat{k}_{c}^{B}=k_{c}^{B *}\end{array}$ & $\begin{array}{l}p^{A *}>\hat{p}>p^{B *} \\
D^{A}=z\left(\hat{k}^{A}\right)-n \hat{k}^{A} \\
\hat{k}^{A}=k_{z}^{A *}=z^{\prime-1}\left(\delta^{A}\right) \\
\hat{k}^{B}=\frac{D^{A}}{a n} \\
\hat{p}=\delta^{B} / c^{\prime}\left(\hat{k}^{B}\right)\end{array}$ & $\begin{array}{l}\hat{p}=p^{A *} \\
D^{A}=a n \hat{k}^{B} \\
\hat{k}^{A}=\frac{D^{A}+\hat{k}_{c}^{A} z\left(\hat{k}_{z}^{A}\right) /\left(\hat{k}_{z}^{A}-\hat{k}_{c}^{A}\right)}{\left[z\left(\hat{k}_{z}^{A}\right) /\left(\hat{k}_{z}^{A}-\hat{k}_{c}^{A}\right)\right]-n} \\
\hat{k}^{B}=c^{\prime-1}\left(\delta^{B} / \hat{p}\right) \\
\hat{k}_{z}^{A}=k_{z}^{A *}=z^{\prime-1}\left(\delta^{A}\right) \\
\hat{k}_{c}^{A}=k_{c}^{A *}\end{array}$ \\
\hline
\end{tabular}
SPECIALIZATION: $k_{c}>k_{z}$

${ }^{16}$ The diagrams for $k_{c}<k_{z}$ are perfectly analogous, and hence are omitted.

${ }^{17}$ The solution of each of these sets of equations is straightforward. In the first column, we immediately know $\hat{p}$ and $\hat{k}^{A}$; knowing $\hat{k}^{A}$, we can solve for $D^{A}$ and thus for $\hat{k}^{B}$. In the second set, we again immediately know $\hat{k}^{A}$; we therefore can calculate $\hat{k}^{B}$ and $D^{A}$, and hence $\hat{p}$. In the final column, we know $\hat{p}$, and can immediately calculate $\hat{k}^{B}$. Knowing that, we can calculate $D^{A}$ and $\hat{k}^{A}$. The case of $k_{c}<k_{z}$ is identical; simply reverse the superscripts $A$ and $B$. 

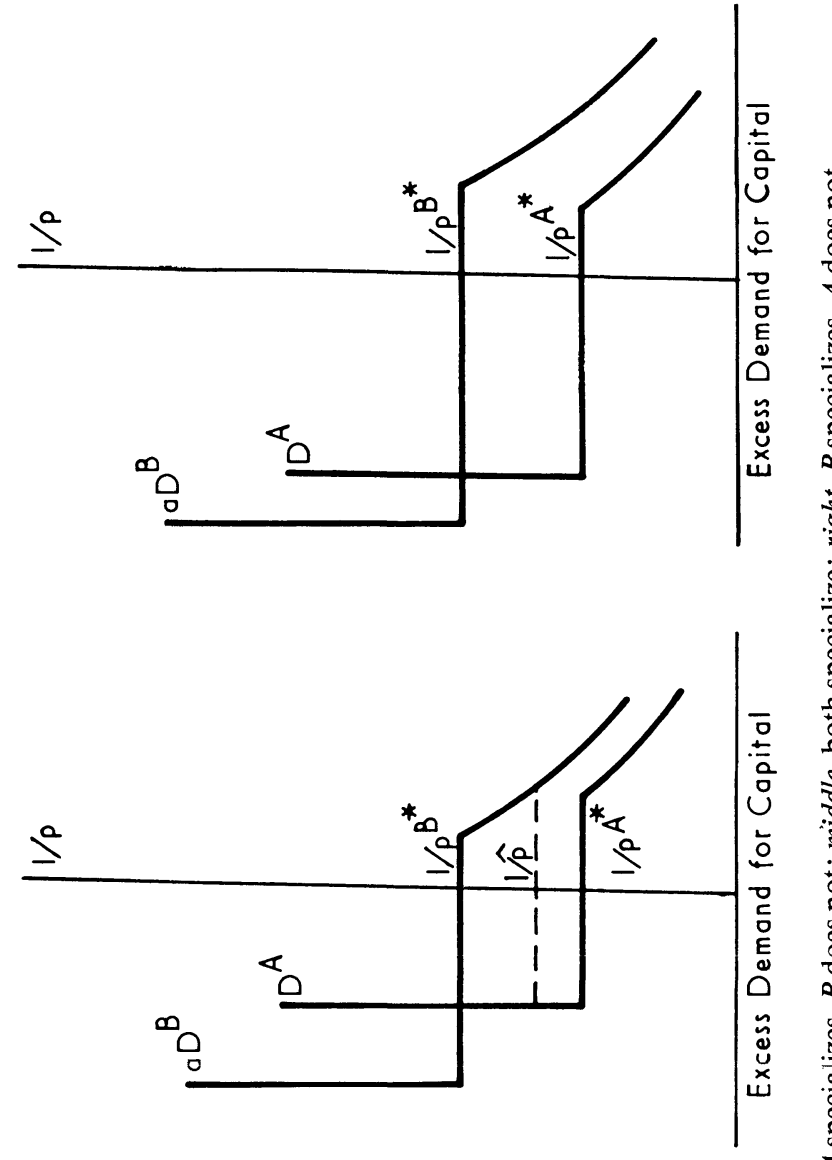

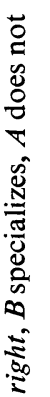

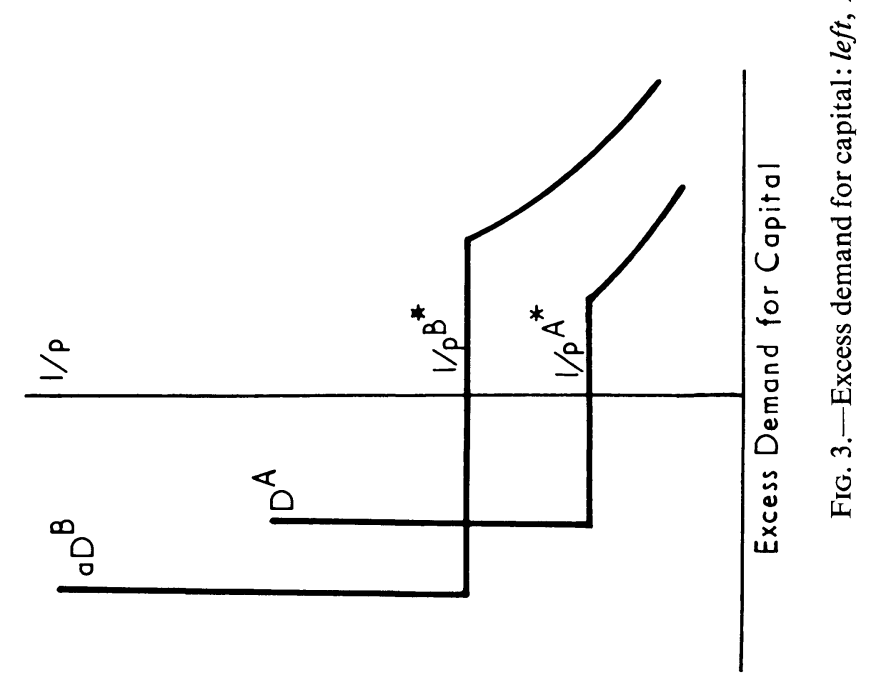



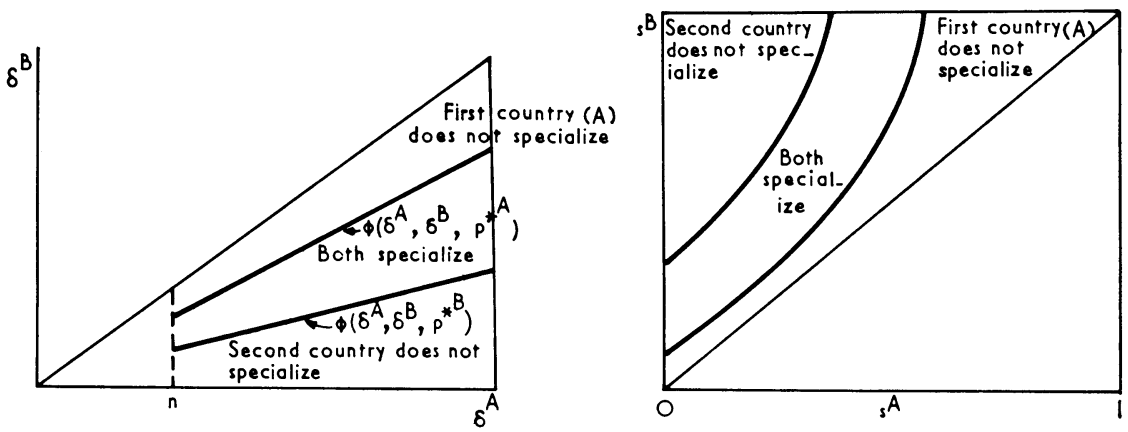

Fig. 4.-Patterns of long-run specialization: left, rational savings behavior $\left(k_{c}>k_{z}\right)$; right, Marxian savings behavior $\left(k_{c}>k_{z}\right)$.

How does the pattern of specialization depend on $\delta^{A}$ and $\delta^{B}$ ? In figure 4 we have depicted the patterns of specialization for fixed $a$, for the case $k_{z}<$ $k_{c}$. The boundary between the situation where only the economy with the low rate of time preference (high savings rate) specializes and where both specialize is given by (if $k_{c}>k_{z}$ ),

$$
\Phi\left(\delta^{A}, \delta^{B}, \hat{p}\right)=z\left(\hat{k}^{A}\right)-n \hat{k}^{A}-a n \hat{k}^{B}=0,
$$

where

$$
\hat{k}^{A}=z^{-1}\left(\delta^{A}\right)
$$

and

$$
\hat{k}^{B}=c^{\prime-1}\left(\frac{\delta^{B}}{\hat{p}}\right),
$$

and where $\hat{p}=p^{A *}$, where $p^{A *}$ is the pre-trade price in country $A$ (high rate of time preference). Thus

$$
\frac{d \delta^{B}}{d \delta_{\Phi=0}^{A}}=\left\{\left[\left(\delta^{A}-n\right)-a n \frac{\partial \hat{k}^{B}}{\partial \hat{p}} \frac{\partial \hat{p}}{\partial \hat{k}_{z}^{A}}\right] \frac{1}{z^{\prime \prime}\left(\hat{k}^{A}\right)}\right\} /\left[a n / c^{\prime \prime}\left(\hat{k}^{B}\right) \hat{p}\right]>0,
$$

provided $k_{z}<k_{c}$, since then as $\hat{k}_{z}^{A}$ increases, $\hat{p}$ decreases, and as $\hat{p}$ decreases, $\hat{k}^{B}$ decreases.

Similarly, the boundary, between the situation where only the economy with the high rate of time preference (low savings rate) specializes and where both specialize, is given by equation (12), where again $\hat{k}^{A}$ and $\hat{k}^{B}$ are given by (12a) and (12b), but now $\hat{p}=p^{B *}$, the pre-trade price in the second country. Thus

$$
\frac{d \delta^{B}}{d \delta_{\Phi=0}^{A}}=\frac{\left(\delta^{A}-n\right) / z^{\prime \prime}\left(\hat{k}^{A}\right)}{\operatorname{an}\left(d k_{c} / d k_{z}\right) / z^{\prime \prime}\left(\hat{k}^{B}\right)}>0 .
$$

Finally, we observe that if $\Phi\left(\delta^{A}, \delta^{B}, \hat{p}\right)>0$ when $\hat{p}=p^{A *}$, then $A$ does not specialize, and if $\Phi\left(\delta^{A}, \delta^{B}, \hat{p}\right)<0$ when $\hat{p}=p^{B *}, B$ does not 
specialize. Since when $\hat{p}=p^{A *}, \Phi_{2}>0$, and when $\hat{p}=p^{B *}, \Phi_{2}>0$, above $\Phi\left(\delta^{A}, \delta^{B}, p^{* A}\right)$ only the second country $(B)$ specializes, and below $\Phi\left(\delta^{A}, \delta^{B}, p^{* B}\right)$ only the first country $(A)$ specializes. In figure 4 (right), we have drawn the analogous diagram for the Marxian savings assumption. ${ }^{18}$

\section{Trade Policy}

In this section we consider the implications of trade policy for the long-run equilibrium of the economy. We focus our attention on the Marxian version of our model. The imposition of a tariff, in addition to the usual terms of trade effect, has an effect on capital accumulation in both countries. This means, in particular, that long-run excess demand or offer curves are quite different from the short-run curves. ${ }^{19}$ In figure 5 , we have depicted both of these curves. (The short-run curves depend, of course, on the value of the capital-labor ratio. ${ }^{20}$ )

${ }^{18}$ Another way of viewing the pattern of specialization is in terms of the relative size parameter, $a$. Let $k_{c}>k_{z}$. (1) If $A$ specializes, and $B$ does not, as $a \rightarrow \infty, \hat{k}^{B} \rightarrow k^{B *}$. From table 2, since $n-z /\left(k_{z}-k_{c}\right)>0, d \hat{k}^{B} / d a<0$, so $\hat{k}^{B}>k^{B *}$ for $a<\infty$. Since $k_{c}^{A *}>k^{A *}>k_{z}^{B *}$, and $\hat{k}^{A}=k_{z}^{A *}, k^{A *}>\hat{k}^{A}$. For $B$ to be nonspecialized, $\hat{k}^{B}<k_{c}^{B *}$, so $a \geq D^{A} / n k_{c}^{B *} \equiv \tilde{a}$. (2) If $B$ specializes and $A$ does not, then as $a \rightarrow 0$, $\hat{k}^{A} \rightarrow k^{A *}$. From column [3] of table 2, since $z /\left(k_{z}-k_{c}\right)-n<0, d \hat{k}^{A} / d a<0$, so $\hat{k}^{A}<\hat{k}^{A *}$ for $a>0$. Since $\hat{p}=p^{A *}>p^{B *}$, and $c^{\prime \prime}<0, \hat{k}^{B}>k_{\mathrm{c}}^{B *}>k^{B *}$. For $A$ to be nonspecialized, $\hat{k}^{A} \geq k_{z}^{A *}$, so $a \leq\left[z\left(k_{z}^{A *}\right)-n k_{z}^{A *}\right] / n \hat{k}^{B} \equiv \tilde{\tilde{a}}$. (3) If $\tilde{\tilde{a}} \leq a \leq \tilde{a}$, both countries specialize, and $\hat{k}^{A}$ has the same value as in the first case. Also $\hat{k}^{B}$ decreases as $a$ increases; but $\hat{k}^{B}=k_{c}^{B *}$ if $a=\tilde{a}$. Thus, $\hat{k}^{B} \geq k_{c}^{B *} \geq k^{B *}$. If $k_{c}<k_{z}$ we obtain the following results: (1) if $B$ specializes and $A$ does not, as $a \rightarrow 0, \hat{k}^{A} \rightarrow k^{A *}$. The denominator of the expression for $\hat{k}^{A}$ is equal to $\left(n-\delta^{A}\right)+\left[\left(\delta^{A}-z\right) /\left(k_{z}-k_{c}\right)\right]$ $=\left(n-\delta^{A}\right)-\left(z-r k_{z}+r k_{c}\right) /\left(k_{z}-k_{c}\right)<0$, since by assumption $\delta^{A}>n$. Thus, $d \hat{k}^{A} / d a<0$, so $\hat{k}^{A}<k^{A *}$. Since $k_{c}^{B *}<k^{B *}<k_{z}^{B *}$, and $\hat{k}^{B}=k_{z}^{B *}, \hat{k}^{B}>k^{B *}$. For $A$ to be nonspecialized, $\hat{k}^{A} \geq k_{c}^{* A}$, so $1 / a \geq D^{B} / n k_{c}^{A *} \equiv 1 / \tilde{a}^{\prime}$. (2) If $A$ specializes and $B$ does not, as $a \rightarrow \infty, \hat{k}^{B} \rightarrow k^{B *}$. As before, it can be shown that $d \hat{k}^{B} / d a>0$. For $B$ to be nonspecialized, $k_{c}^{B *} \leq \hat{k}^{B}$, or, $1 / a \leq\left[z\left(k_{z}^{B *}\right)-n k_{c}^{B *}\right] / n \hat{k}^{A} \equiv 1 / \tilde{\tilde{a}}^{\prime}$. Thus, if $a \geq \tilde{\tilde{a}}^{\prime}, k_{c}^{B *} \leq \hat{k}^{B}$. Since $\hat{p}=p^{B *}>p^{A *}, \hat{k}^{A} \geq k_{c}^{A *}<k^{A *}$, so $\hat{k}^{A}$ may be less or greater than $k^{A *}$. (3) If $\tilde{a}^{\prime}<a<\tilde{\tilde{a}}^{\prime}$, both countries specialize, and $\hat{k}^{B}$ has the same value as in the first case, while $\hat{k}^{A}$ may be greater than $k^{A *}$, as in the second case.

${ }^{19}$ The static theory of the optimum tariff is thus no longer directly applicable. The optimal tariff policy will depend not only on the home country's rate of time preference but also on the speeds of adjustment in the foreign country.

${ }^{20}$ Note that the long-run curves are not necessarily everywhere more elastic than the short-run curves (in particular, if $k_{z}<k_{c}$ ). The derivation of the long-run curve has already been described. The derivation of the short-run curve is straightforward: If $k_{z}<k_{c}$ as $1 / p$ (the price of capital goods relative to consumption goods) increases, the wage-rentals ratio increases, and hence $k_{z}$ and $k_{c}$ increase. Profits, and therefore investment, decrease while output of capital goods increases, so excess supply increases. Eventually, $k_{z}=k$. The price at which this occurs is the capital-goods specialization price: For all greater prices of capital goods, the economy specializes in capital goods. Excess supply is given by $z(k)-s z^{\prime}(k) k$, and is independent of price. Note that the long-run supply with specialization is given by $z(\hat{k})-s z^{\prime}(\hat{k}) \hat{k}$, and since $z^{\prime}(1-s)-s z^{\prime \prime} k>0$, if $\hat{k}<k^{*}$, excess supply with specialization is greater in the short run than the long run. Similarly, as we lower the price, excess demand increases, and $k_{z}$ and $k_{\mathrm{c}}$ fall, until $k_{\mathrm{c}}=k$; the price at which this occurs is the consumptiongoods specialization price: For all smaller prices of capital goods, the economy 


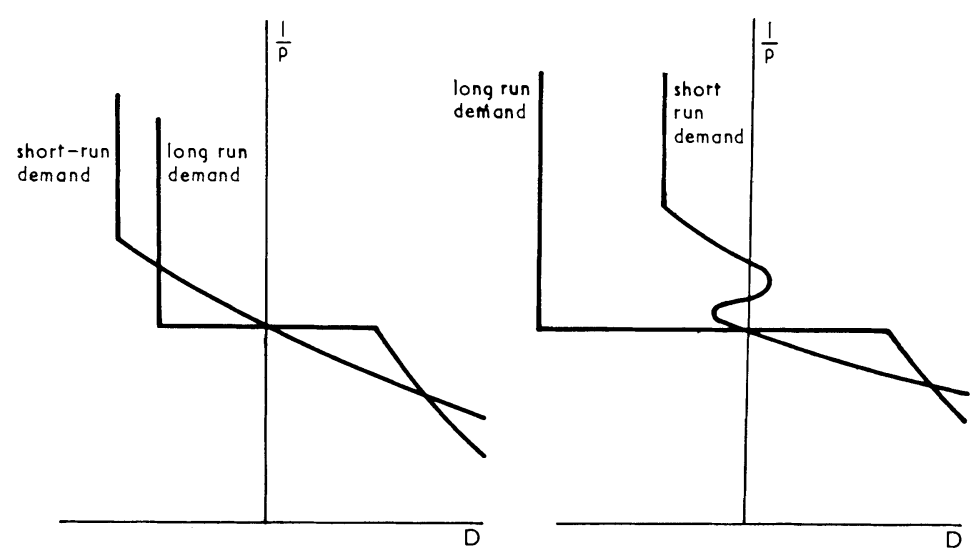

FIG. 5.--Excess demand for capital goods in the short and long run: left, $k_{\mathrm{c}}>k_{z}$; right, $k_{\mathrm{c}}<k_{z}$.

A second way in which trade policy in this dynamic model differs from the usual analysis is that, when there is specialization, no distortions in production need result from the imposition of tariffs: For the given endowments of each country, production may be exactly as it would have been had there been no tariffs.

To see somewhat more clearly the effects of trade policy in the long run in a dynamic economy, we examine in detail the effects of trade policy for the consumption-goods exporting country, leaving the other cases to the reader. ${ }^{21}$

a) Assume $k_{c}>k_{z}$. If $A$ (capital-goods exporter) does not specialize, its internal price $\tilde{p}^{A}$ (as well as the international price, $\hat{p}$ ) is equal to its pre-trade value, $p^{A *}$. Trade policy affects only the internal price in $B, \tilde{p}^{B}$. As usual, consumption per man in the second country is simply production less exports: $c\left(\hat{k}^{B}\right)-n \hat{k}^{B} \mid \hat{p}$.

If we impose a tariff at the rate $(1-\tau) / \tau$ (with proceeds spent on consumption), the price of capital goods will be $1+(1-\tau) / \tau=1 / \tau$ times its free-trade price, so the price of consumption goods relative to capital goods will be $\tau \hat{p}$. Thus, $c^{\prime}\left(\hat{k}^{B}\right) \hat{p} \tau=n / s^{B}$. As $\tau$ increases $\hat{k}^{B}$ increases, and $c$ increases until $\hat{k}^{B}=\bar{k}^{B} \equiv c^{-1}(n / \hat{p})$, the value of $k^{B}$ for

specializes in consumption goods. Excess demand is given by $p s c^{\prime}(k) k$. Since $\left[d c^{\prime}(k) k\right] /$ $d k=c^{\prime \prime} k\left[1+c^{\prime} /\left(c^{\prime \prime} k\right)\right]=c^{\prime \prime} k\{1-[\sigma(k) / \alpha(k)]\} \gtrless 0$ as $\sigma \gtrless \alpha$, where $\sigma(k)$ is the absolute value of the elasticity of substitution $\left[c^{\prime}\left(c-c^{\prime} k\right)\right] / c^{\prime \prime} c k$, and $\alpha$ is the share of labor. If $\hat{k}>k$, excess demand for capital goods is larger (smaller) in the short run than in the long run if $\sigma>\alpha(\sigma<\alpha)$. The case of $k_{z}>k_{c}$ may be handled analogously, with the important modification that in the region of nonspecialization, excess demand may not be monotonic (see below, n. 29).

${ }^{21}$ It will be assumed throughout that the rate of interest from the point of view of the domestic producer is fixed. (For the Marxian model, for example, this implies tariff revenues are spent on consumption commodities.) 
which the rate of return on capital equals the rate of growth (the golden rule) (see fig. 6).

Equilibrium in the capital-goods markets requires that demand for capital goods equals supply:

$$
\left(\hat{k}^{A}-k_{c}^{A *}\right) /\left(k_{z}^{A *}-k_{c}^{A *}\right) z\left(k_{z}^{A *}\right)=n \hat{k}^{A}+a n \hat{k}^{B} .
$$

Thus, if $\hat{k}^{B}$ is increased, $A$ must export more capital goods, which, since $k_{z}<k_{c}$, means $\hat{k}^{A}$ is reduced, and hence $c^{A}=\left(w^{*}+r^{A} k^{A}\right) / \hat{p}$ is reduced: $B$ 's gains are at the "expense" of $A$. Moreover, it is easy to show that total consumption $\left(L^{A} C^{A}+L^{B} C^{B}\right)$ may either increase or decrease. This also implies an upper bound on the value which $\tau$ can attain without changing the pattern of specialization, since $\hat{k}^{A} \geq k_{z}^{A *}$.
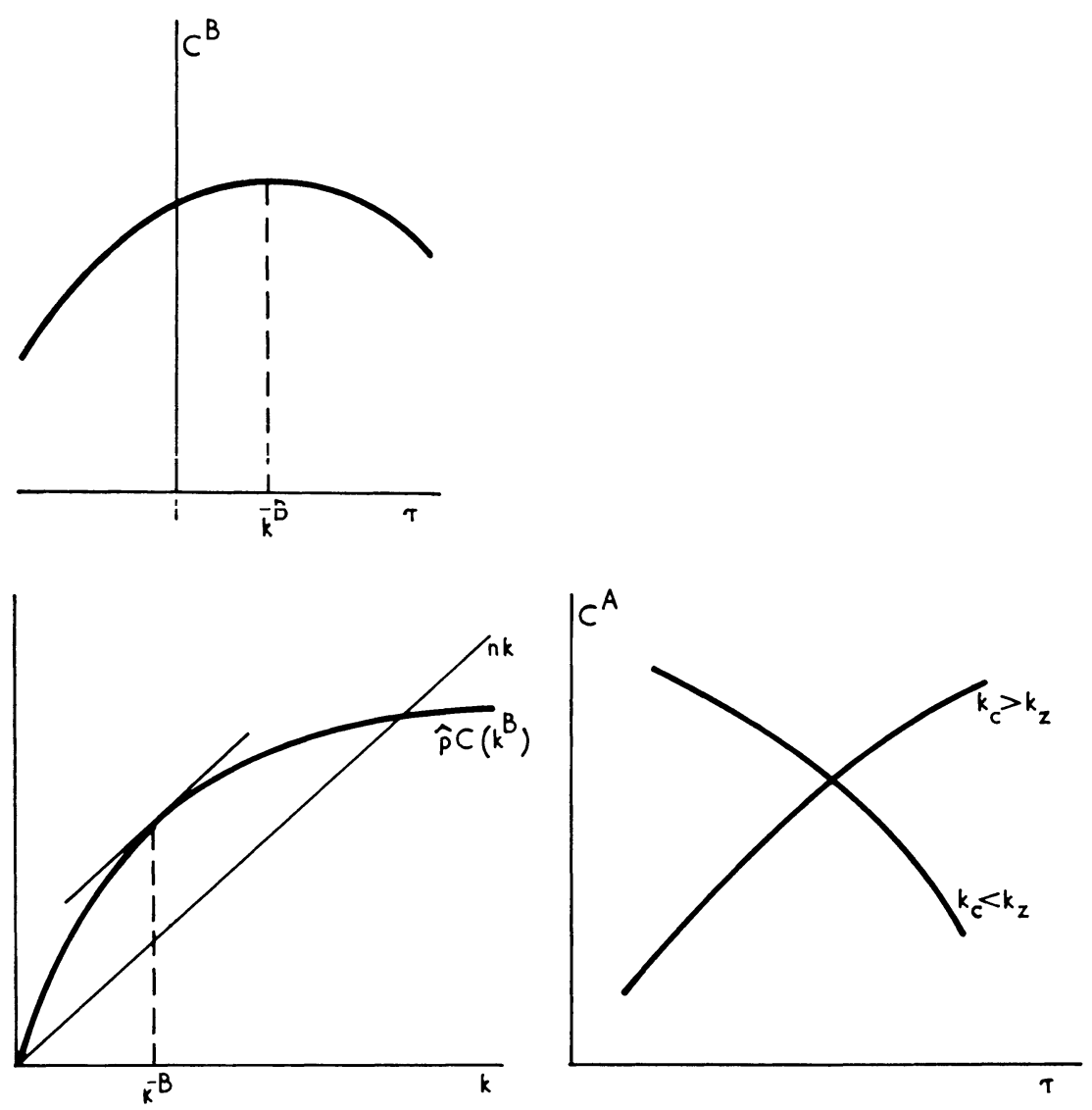

FIG. 6.-Effects of export subsidy on consumption when capital-goods exporter is not specialized: top, long-run consumption in consumption-goods exporter; bottom left, determination of "golden rule" tariff; bottom right, long-run consumption in capital-goods importer. 
But if $k_{c}<k_{z}$, as the consumption-goods exporter increases his capitallabor ratio, the investment-goods exporter must increase his capital-labor ratio, which leads to a higher per capita consumption. Thus both countries may have higher levels of per capita consumption as the result of the imposition of a tariff by one country.

b) If both countries specialize, then the capital-goods exporter's supply of capital is (in the long run) completely inelastic: if $k_{c}>k_{z}$, $m^{*} \equiv z\left(k_{z}^{A *}\right)-n k_{z}^{A *}$. As before, the international balance-of-payments condition determines $\hat{k}^{B}$, so there is no capital accumulation effect in this case: $\hat{k}^{B}=m^{*} / n a$. The sole effect of the trade policy is to change the terms of trade. The internal price in $B$ is determined by $\tilde{p}^{B}=n / c^{\prime}\left(\hat{k}^{B}\right) s^{B}$. Consumption per man is determined by $c\left(\hat{k}^{B}\right)-n \hat{k}^{B} \mid \hat{p}$. As $\hat{p}$, the international price of consumption goods is increased, $c^{B}$ increases. Thus, if $B$ imposes a tariff at the rate $(1-\tau) / \tau, \tau \hat{p}=\tilde{p}^{B}$. As $\tau$ decreases, $\hat{p}$ increases. There is a limit to the increase in $\hat{p}: \hat{p}<\hat{p}^{A *}$. For at $\hat{p}=p^{A *}, A$ will stop specializing. As $c^{B}$ increases, $c^{A}$ decreases: $B$ 's gains are at the "expense" of $A$. Identical results obtain if $k_{c}<k_{z}$.

The case where the first country specializes and the second does not may be handled analogously.

\section{Extensions of the Analysis}

It should be clear that the results described in this paper are much more general than the specific assumptions employed. In this section, we shall sketch two extensions of the analysis, one involving modifications of the technology assumptions and the other involving a modification of the savings assumption.

First, it should be noted that the results do not depend on the fact that one of the two goods traded is a capital good. Indeed, the analysis could have been much simplified if we had assumed that in each country there are three sectors, one producing capital goods (not traded) and two producing different consumption goods, food and clothing. ${ }^{22}$ Since capital is required for production but cannot be traded, both countries must produce capital goods. In the long run, the rate of return (the marginal product of capital in the capital-goods sector) will be different in the two countries: ${ }^{23}$

${ }^{22}$ This is essentially the model analyzed by Samuelson (1965).

${ }^{23}$ In the Marxian model we replace, as usual, $\delta^{i}$ by $n / s^{i}$. In the intemporal utility maximization model, the objective function is now $\int U(c, f) e^{-(\delta-n) t} d t$. The necessary conditions for utility maximization are given by $-d U_{c} / d t+\delta=-d U_{f} / d t+\delta=r$. In addition, of course, the usual static conditions that

$$
\begin{gathered}
r \geq p_{f} f^{\prime}\left(k_{f}\right), \quad r \geq p_{c} c^{\prime}\left(k_{c}\right), \quad r \geq z^{\prime}\left(k_{z}\right) ; \\
w \geq p_{f}\left(f-k_{f} f^{\prime}\right), \quad w \geq p_{c}\left(c-k_{c} c^{\prime}\right), \quad w \geq z-k_{z} z^{\prime} ; \\
\left(r-p_{f} f^{\prime}\right) f=0, \quad\left(r-p_{c} c^{\prime}\right) c=0, \quad\left(r-z^{\prime}\right) z=0,
\end{gathered}
$$

must be satisfied; the transversality conditions yield $\delta=r$. 
$z^{\prime}\left(k_{z}^{A *}\right)=\delta^{A} \neq \delta^{B}=z^{\prime}\left(k_{z}^{B *}\right)$. Since for each country the rate of return in each producing sector must be the same, we have

$$
\begin{aligned}
& r=z^{\prime}\left(k_{z}^{A *}\right)=\max \left[p_{c} c^{\prime}\left(k_{c}^{A *}\right), p_{f} f^{\prime}\left(k_{f}^{A *}\right)\right] \\
& r=z^{\prime}\left(k_{z}^{B *}\right)=\max \left[p_{c} c^{\prime}\left(k_{c}^{B *}\right), p_{f} f^{\prime}\left(k_{f}^{B *}\right)\right],
\end{aligned}
$$

where $f\left(k_{f}\right)$ is output per worker in the food industry, $k_{f}$ capital per worker in the food industry, and $p_{f}$ the ratio of the price of food to capital. If neither country specialized, we would have $z^{\prime}\left(\hat{k}_{z}^{A}\right)=p_{c} c^{\prime}\left(\hat{k}_{c}^{A}\right)=$ $p_{f} f^{\prime}\left(\hat{k}_{f}^{B}\right)=p_{c} c^{\prime}\left(\hat{k}_{c}^{B}\right)=p_{f} f^{\prime}\left(\hat{k}_{f}^{B}\right)=z^{\prime}\left(\hat{k}_{z}^{B}\right)$, which, of course, is impossible. Hence, at least one of the two countries must specialize. The pattern of specialization is seen clearly from figure 7 .

The country with the higher rate of time preference (lower savings rate) exports the labor-intensive consumption good. This is true no matter what the ranking of capital intensities, that is, whether $k_{c} \gtrless k_{z}, k_{c} \gtrless k_{f}$, or $k_{f} \gtrless k_{z}$.

All the other aspects of the analysis may similarly be carried out with the qualitative results identical with those above.

The second way in which the analysis may be modified is to introduce alternative assumptions about savings behavior. In particular, what

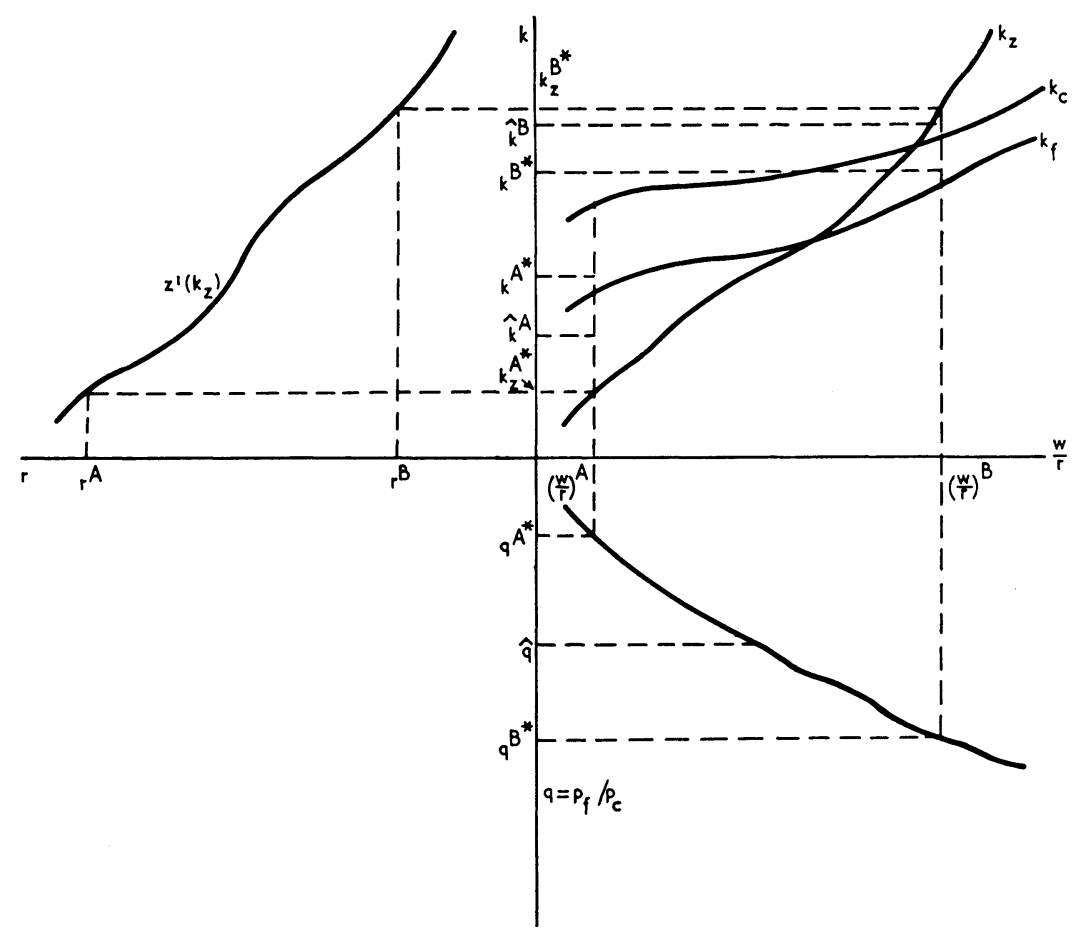

Fig. 7.-Determination of long-run equilibrium pre- and after trade: three-commodity model. 
happens if we let the rate of pure time preference no longer be independent of the level of steady-state consumption? If, for instance, we assume a stationary utility function of the form (see Beals and Koopmans 1967) $U\left(c_{1}, c_{2}, \ldots, c_{n}\right)=V\left[c_{1}, U\left(c_{2}, \ldots, c_{n}\right)\right]$, where $c_{i}$ is consumption per capita in the $i$ th period, and where $\delta(c)=1 /[\partial V(c, U) / \partial U]_{U=U(c, c, \ldots)}-1$ or in one continuous time formulation due to Uzawa (1968b) $U=$ $\int_{0}^{\infty} U(c) e^{-\Delta(t)} d t$, where $\dot{\Delta}(t)=\delta[U(c)]$, most of the qualitative results still hold, although it is now possible for factor prices to be completely equalized. Consider, for instance, the small country in a large world model. In figure 8 , we have drawn pre- and post-trade schedules of consumption as a function of $r$. We have also drawn the pure rate of time preference as a function of steady-state levels of per capita consumption.
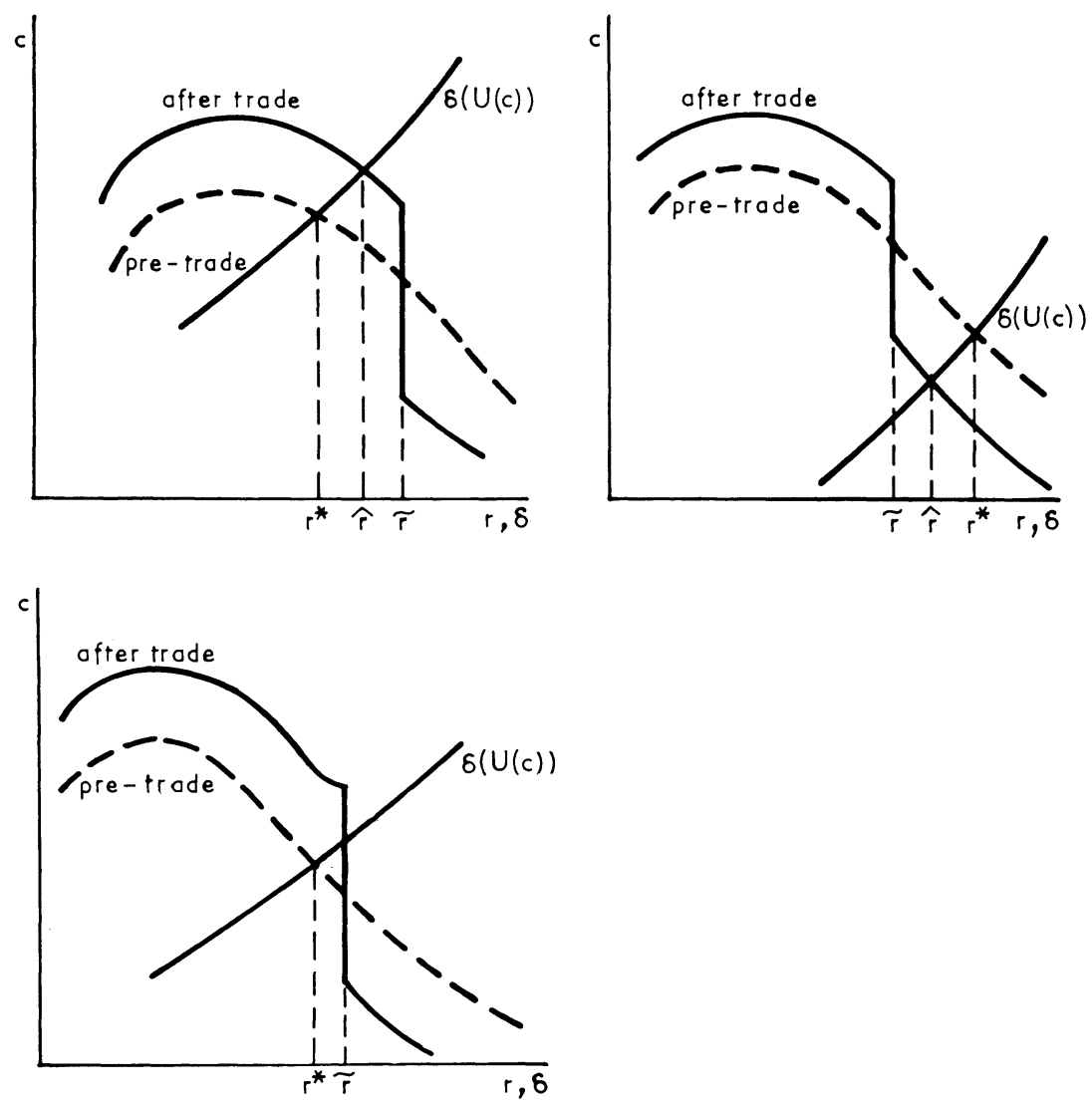

Fig. 8.- - Long-run consumption and interest rates pre-trade and after trade with variable rate of time preference: top left, long-run pre-trade $r$ smaller than after trade; top right, long-run pre-trade $r$ larger than after trade; bottom, complete factor price and interest rate equalization. 


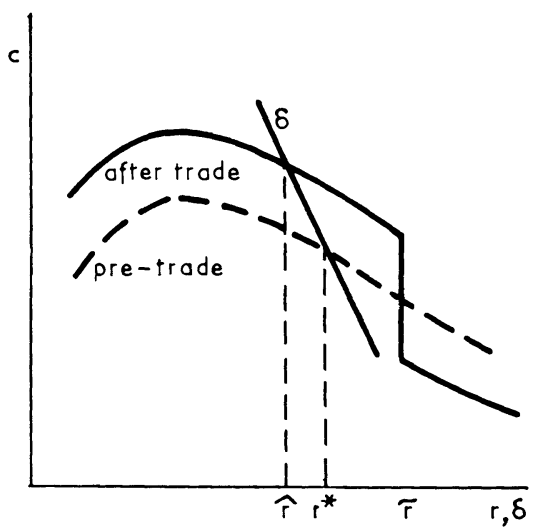

Fig. 9.--Long-run consumption and interest rates pre-trade and after trade with variable rate of time preference: free-trade interest rates differentials greater than pre-trade.

In the diagram, we have followed Uzawa in assuming that the curve is upward sloping ( $\tilde{r}$ is the other country's interest rate). The opening of trade then results in the reduction of interest rate differentials $(|\hat{r}-\tilde{r}|<$ $\left.\left|r^{*}-\tilde{r}\right|\right)$ and, if the country exports capital goods, wage-rentals ratio differentials are also reduced. But if the country exports consumption goods, just the opposite may occur even if $k_{c}<k_{z}$ (although in this case $r$ is increased, so is $p$ ). In figure 8 (bottom), we have drawn the case where factor prices are completely equalized.

On the other hand, if the pure rate of time preference decreases with increasing consumption, then steady-state interest rate differentials may increase, as in figure 9 , in which case, even if $k_{z}>k_{c}$, after-trade wagerentals ratio differentials may be larger than pre-trade wage-rental ratio differentials.

\section{Appendix on Dynamics}

The discussion of the text was primarily limited to what is usually called comparative dynamics: comparisons of steady-state paths. Although the two alternative savings assumptions yield qualitatively identical long-run results, the dynamic path by which the steady state is approached may differ markedly. In this Appendix we briefly investigate the nature of these paths.

\section{A. Small-Country Case}

If one country is much smaller than the other (the "rest of the world"), then the price ratio $\hat{p}$ can be assumed to be independent of what the country does. ${ }^{24}$ If it were to produce only consumption goods, the value of national income would be given by $\hat{p} c(k)$, while if it produced only capital goods, national income would be given by $z(k)$ (see fig. A1).

${ }^{24}$ Throughout this section we omit the country superscript. 


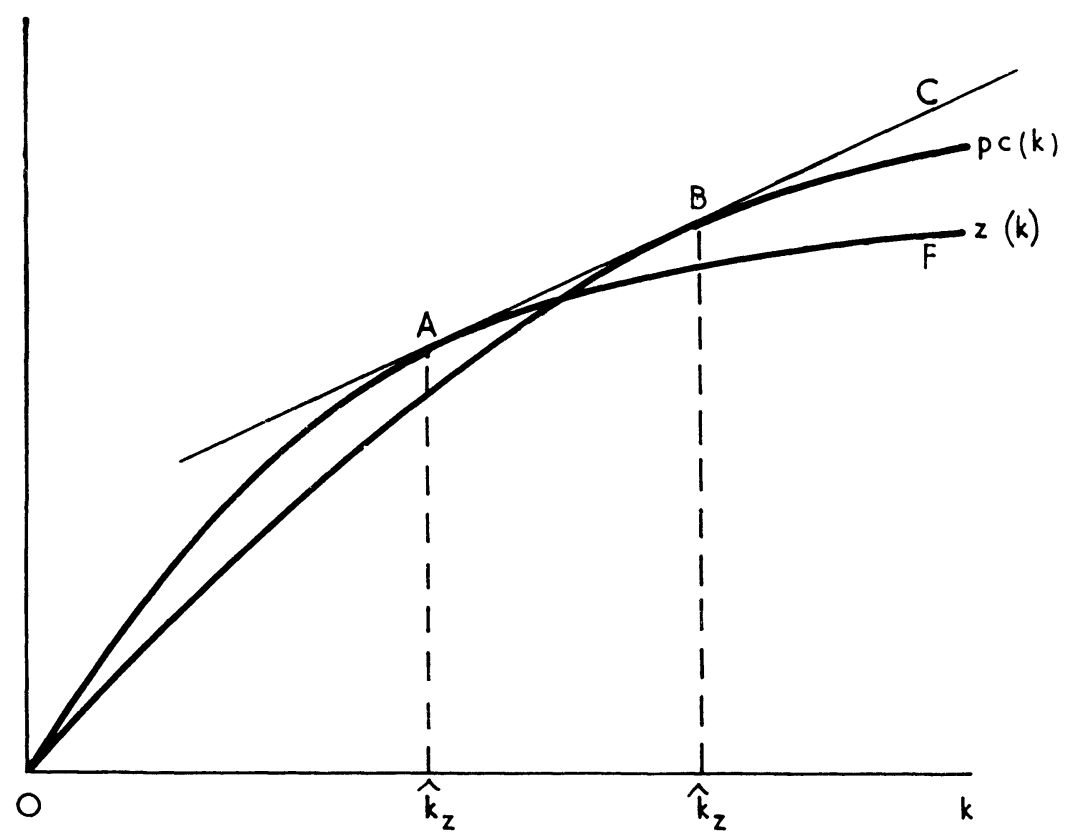

FIG. A1.-Determination of patterns of specialization for small country with free trade.

Since both production functions have constant returns to scale, the country can produce anywhere along $O A B C$ (the convex hull of the two production functions). Since $A B$ is tangent to both $O A F$ and $O B C, z^{\prime}\left(\hat{k}_{z}\right)=p c^{\prime}\left(\hat{k}_{c}\right)$, where $\hat{k}_{z}$ denotes the value of $k$ at $A$, and $\hat{k}_{c}$ that at $B$, that is, $\hat{k}_{z}$ and $\hat{k}_{c}$ are the capital intensities corresponding to $\hat{p}$ in figure 1 . If the capital-goods sector is less capital intensive than the consumption-goods sector, if $k<\hat{k}_{z}$, production is specialized in investment goods; if $k>\hat{k}_{c}$, in consumption goods. (If $k_{c}<k_{z}$, reverse the inequalities.)

The dynamics are identical with those of a one-sector model with production function $O A B C$, denoted by $\hat{f}(k)$.

a) Marxian savings. In figure A2 we have plotted $r$ (the slope of $O A B C$ ) as a function of $k$. Since $k=(s r-n) k, k$ increases (or decreases) monotonically to $\hat{k}$, the long-run equilibrium value. ${ }^{25}$

b) Rational savings. The optimum trajectory (if one exists) is described by the following differential equations:

$$
\begin{gathered}
-\frac{u^{\prime \prime} c}{u^{\prime}} \frac{\dot{c}}{c}=r-\delta, \\
k=\hat{f}(c)-n k-c,
\end{gathered}
$$

${ }^{25}$ If the savings rate in the small country is identical with that in the rest of the world, the opening of trade has no effect, $\hat{k}=k^{*}$, its pre-trade value. 


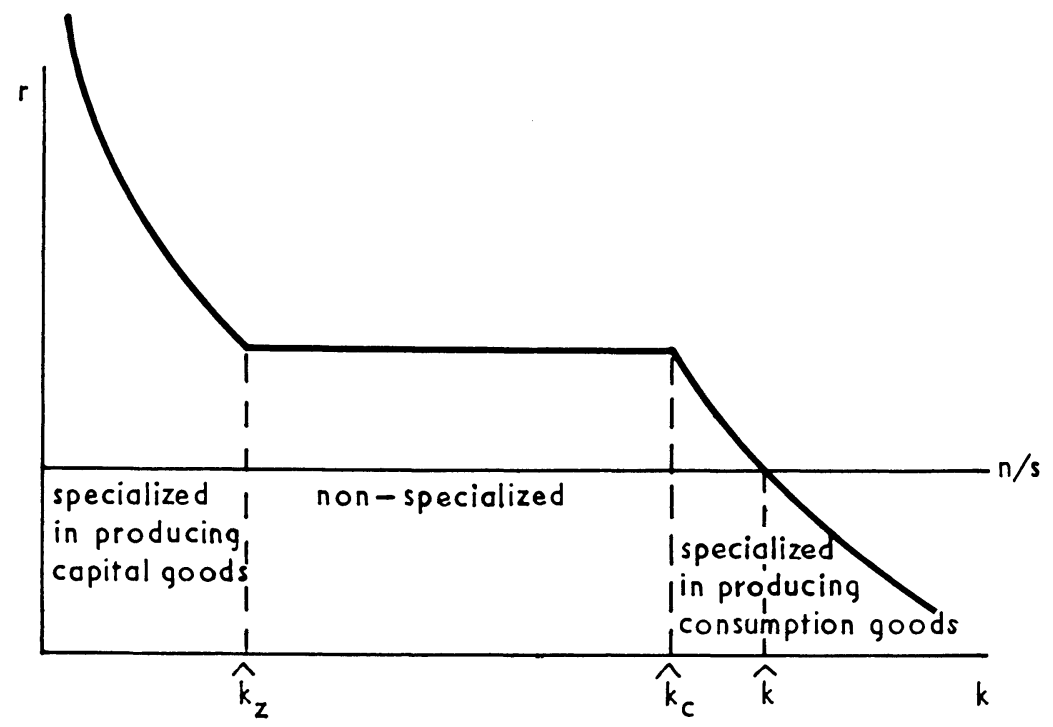

Fig. A2.-Determination of short- and long-run behavior of small country with free trade: Marxian savings $\left(k_{c}>k_{z}\right)$.

with the boundary conditions

$$
\begin{gathered}
k(0)=k_{0}, \\
\lim _{t \rightarrow \infty} u^{\prime}(c) k e^{-\delta t} \rightarrow 0 .
\end{gathered}
$$

The solution is depicted diagrammatically in figures $\mathrm{A} 3$ and $\mathrm{A} 4$. The $k=0$ curve is concave and attains its maximum at $\hat{f}^{\prime}(\tilde{k})=n \cdot{ }^{26}$ Since $\dot{c}=0$ at $\hat{f}^{\prime}(\hat{k})=\delta$, and since $\delta>n, \hat{k}<\tilde{k}$. Since $\partial \dot{k} / \partial c<0$, above the $\dot{k}=0$ curve, $\dot{k}<0$, below it $\dot{k}>0$. To the left of the $\dot{c}=0$ curve, $r>\delta$, so $\dot{c}>0$, to the right $\dot{c}<0 .{ }^{27}$

\section{B. The General Case}

We consider now the general case where country A has $v$ of the world population and country B $(1-v):(a \equiv 1-v / v)$. We limit ourselves here to the case of Marxian savings assumption. Before we draw the detailed phase diagrams, we need to sketch out the patterns of specialization. The results are set forth in table A1, where the following additional notation has been introduced: $\beta\left(k_{z}\right) \equiv z^{\prime}\left(k_{z}\right) k_{z} / z\left(k_{z}\right)$ (share of profit in $z$ sector), $\alpha\left(k_{c}\right) \equiv c^{\prime}\left(k_{c}\right) k_{c} / c\left(k_{c}\right)$ (share of profit in $c$ sector); $N=k_{c} / k_{z}$, the ratio of capital intensities if there is

${ }^{26}$ Since $c_{\dot{k}=0}=f(k)-n k, d c / d k_{\dot{k}=0}=f^{\prime}-n$, and $d^{2} c / d k^{2} \dot{k}=0=f^{\prime \prime}$.

${ }^{27}$ The only modification in the usual analysis arises if the rate of time preference of the small country is identical with that of the rest of the world. Then $r=\delta$ for $\hat{k}_{z}<k<\hat{k}_{c}$, so there is a region in which $\dot{c}=0$. If $k_{0}<\hat{k}_{z}$, in the long run $\hat{k}=\hat{k}_{z}$; if $k_{0}>k_{c}$, in the long-run $\hat{k}=\hat{k}_{\mathrm{c}}$; if initially we were in long-run no-trade equilibrium, with $\hat{k}_{z}<k_{0}<\hat{k}_{c}$, the opening of trade has no effects; see fig. A4. (The modifications for the case $k_{c}<k_{z}$ are straightforward.) 


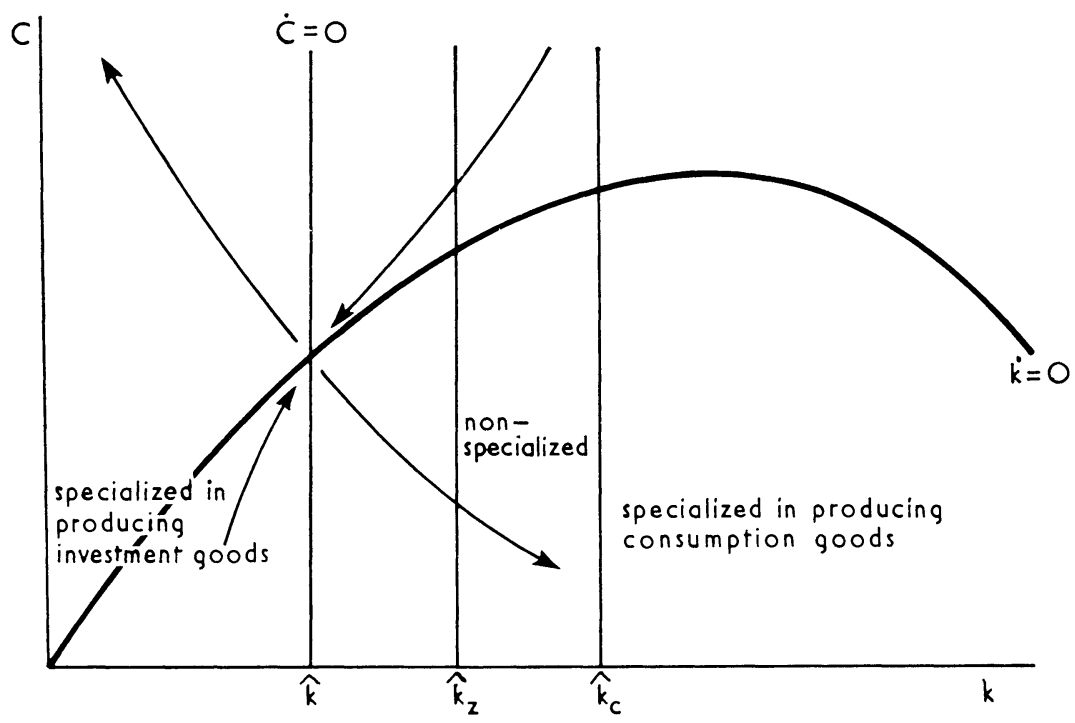

FIG. A3.-Determination of short- and long-run behavior of small country with free trade: rational savings $\left(\delta^{A} \neq \delta^{B}, k_{c}>k_{z}\right)$.

nonspecialization; $\Pi_{c}\left(k_{c}\right)=z^{\prime}\left(k_{c}\right) k_{c}$, profit per worker in $c$ sector; $\tilde{p}_{z}(k)$ price at which country with capital-labor ratio $k$ specializes in $z ; \tilde{p}_{c}(k)$ price at which country with capital-labor ratio $k$ specializes in $c ; \tilde{k}_{z}(p)$ and $\tilde{k}_{c}(p)$ are

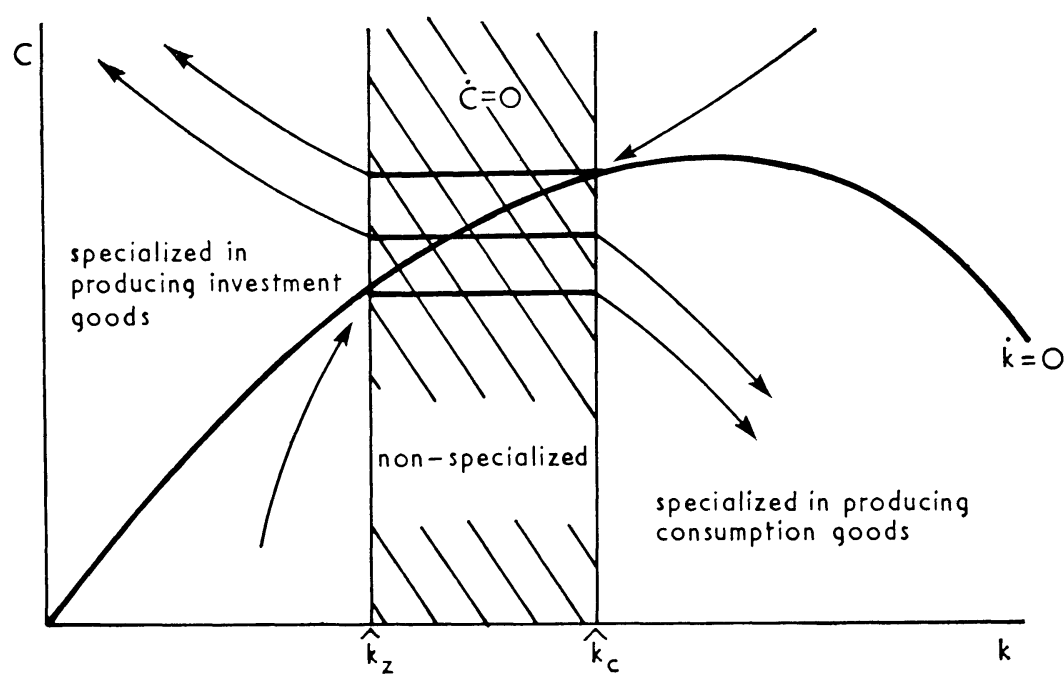

FIG. A4.-Determination of short- and long-run behavior of small country with free trade: rational savings $\left(\delta^{A}=\delta^{B}, k_{c}>k_{z}\right)$. 
the inverses of the above two functions. ${ }^{28}$ Elasticity of substitution in $z$ sector $=\sigma_{z}=-z^{\prime}\left(z-k_{z} z^{\prime}\right) / z z^{\prime \prime} k_{z}$; elasticity of substitution of $c$ sector $=$ $\sigma_{c}=-c^{\prime}\left(c-k_{c} c^{\prime}\right) / c c^{\prime \prime} k_{c}$; proportion of $i$ th country's labor force in $z$ sector $=$ $\rho^{i}=\left(k-k_{c}^{i}\right) /\left(k_{z}^{i}-k_{c}^{i}\right)$.

International equilibrium requires savings to equal production of investment goods, and this is what the equations in the second column of table A1 state for the various specialization patterns. ${ }^{29}$ For each particular pattern of specialization, $\left(k^{A}, k^{B}\right)$ must satisfy certain constraints, and these are set forth in the third column of A1. For instance, if neither country is specialized, for a given value of $k_{z}$ (and hence $k_{c}$ ), as $k^{A}$ increases, for savings to equal investment, $k^{B}$ must decrease (linearly). But, if $k_{c}>k_{z}, k^{A}$ must be less than $k_{c}$, and $k^{B}$ must be greater than $k_{z}$. One of these constraints must eventually become binding. Which does so first depends simply on the following: ${ }^{30}$

If $N>(<) 1$,

the constraint $\left\{\begin{array}{l}k^{A} \leq(\geq) k_{c} \\ k^{B} \geq(\leq) k_{z} \\ k^{B} \leq(\geq) k_{c} \\ k^{A} \geq(\leq) k_{z}\end{array}\right\}$ is binding if $\left\{\begin{array}{l}\beta\left(s^{A} v N+(1-v) s^{B}\right)<(1-v) \\ \beta\left(s^{A} v N+(1-v) s^{B}>(1-v)\right. \\ \beta\left(s^{B}(1-v) N+v s^{A}\right)<v \\ \beta\left(s^{B}(1-v) N+v s^{A}\right)>v\end{array}\right\}$.

The loci along which the respective constraints are just binding are given in table A2. It should be noted that if both production functions are CobbDouglas, all the boundaries are linear, positively sloped, and pass through the origin, and hence cannot intersect. More generally, however, the boundaries may intersect and may be negatively sloped. If the $k^{A} \leq(\geq) k_{c}$ constraint is binding for some value of $k_{c}$, it is binding for all greater values of $k_{z}$ if ${ }^{31}$

$$
\begin{gathered}
\sigma_{c} \leq \sigma_{z} \leq 1, \text { or } \\
\sigma_{c} \leq \sigma_{z} \text { and } s^{A} v N<(1-v)\left(1-s^{B}\right), \text { or } \\
\sigma_{c} \leq\left[1-\alpha\left(k_{c}\right)\right] \text { and } N>1 .
\end{gathered}
$$

Sufficient conditions that the respective boundaries be positively sloped are

${ }^{28}$ For a discussion of specialization prices for the two-sector model, see, for instance, Oniki and Uzawa (1965).

${ }^{29}$ In general, for given $\left(k^{A}, k^{B}\right)$, momentary equilibrium may not be unique. Sufficient conditions for momentary uniqueness are that $\sigma_{c}, \sigma_{z} \geq 1$ or $N>1$. It is required to show that net excess demand, $E$, equals 0 for a unique $p$. If both countries are nonspecialized, $E=\tilde{s} k r-\rho z$, where $\tilde{s}=v s^{A} k^{A}+(1-v) s^{B} k^{B} / k$ and $k=$ $v k^{A}+(1-v) k^{B}$, for which it is known that the above conditions are sufficient (see Drandakis 1963). The other cases follow along analogous lines (see also Bardhan 1965). Bardhan also analyzes the stability of this model when the equilibrium involves nonspecialization or specialization by both countries, but his analysis, besides its nonglobal character, provides little information on the dynamics, except the eventual convergence to balanced growth.

${ }^{30}$ This is obtained simply by substituting $k^{A}=k_{c}$ into the equilibrium condition when both countries are unspecialized, and observing whether the required value of $k^{B} \gtrless k_{z}$, and so on.

${ }^{31}$ Similarly, if the constraint $k^{A} \geq(\leq) k_{z}$ is binding for some values of $k_{z}$, it is for all greater values of $k_{z}$ if $\sigma_{c} \geq \sigma_{z} \geq 1$. To prove these results, we simply make use of the facts cited in the second footnote of table A2. 


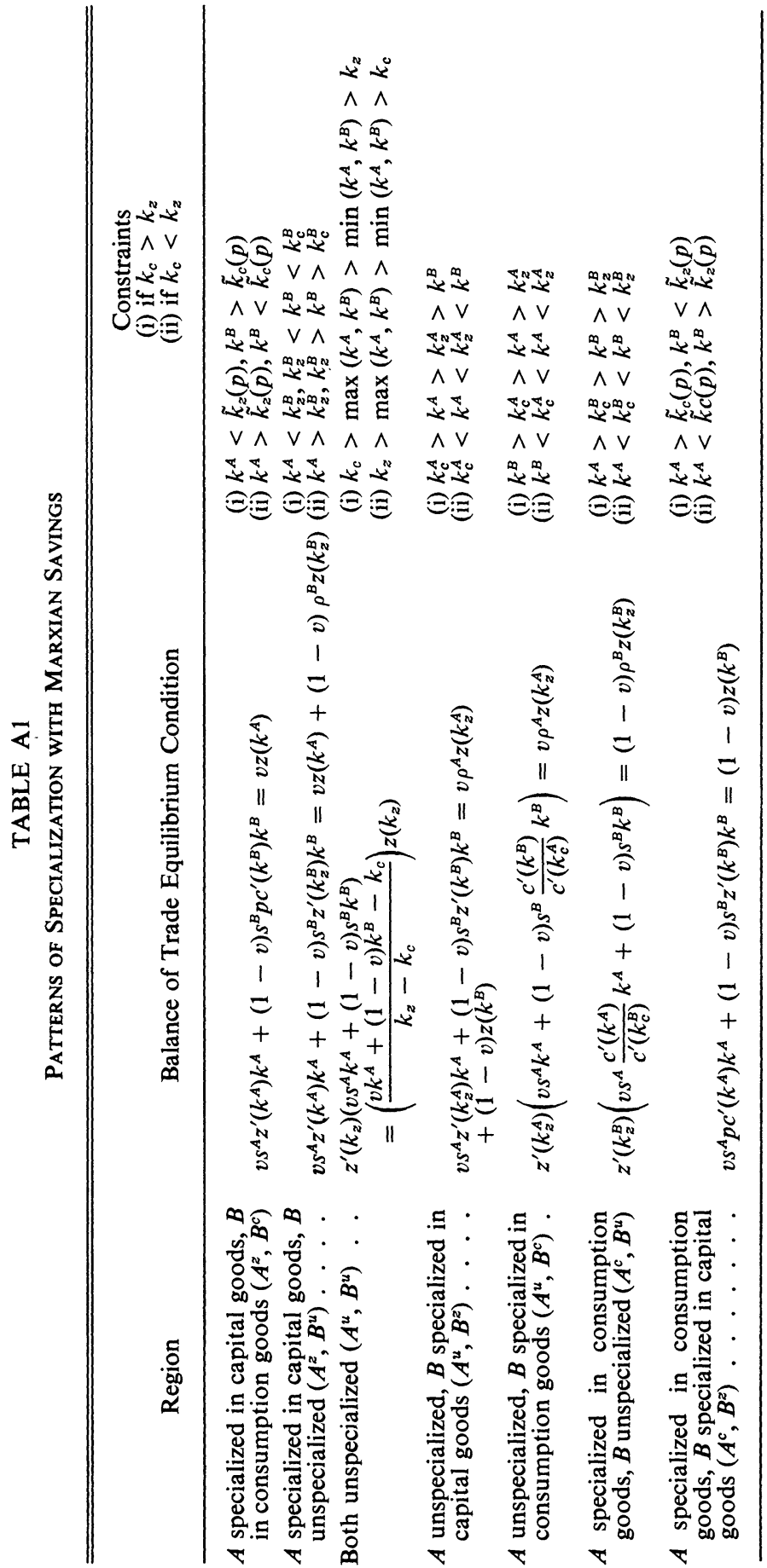




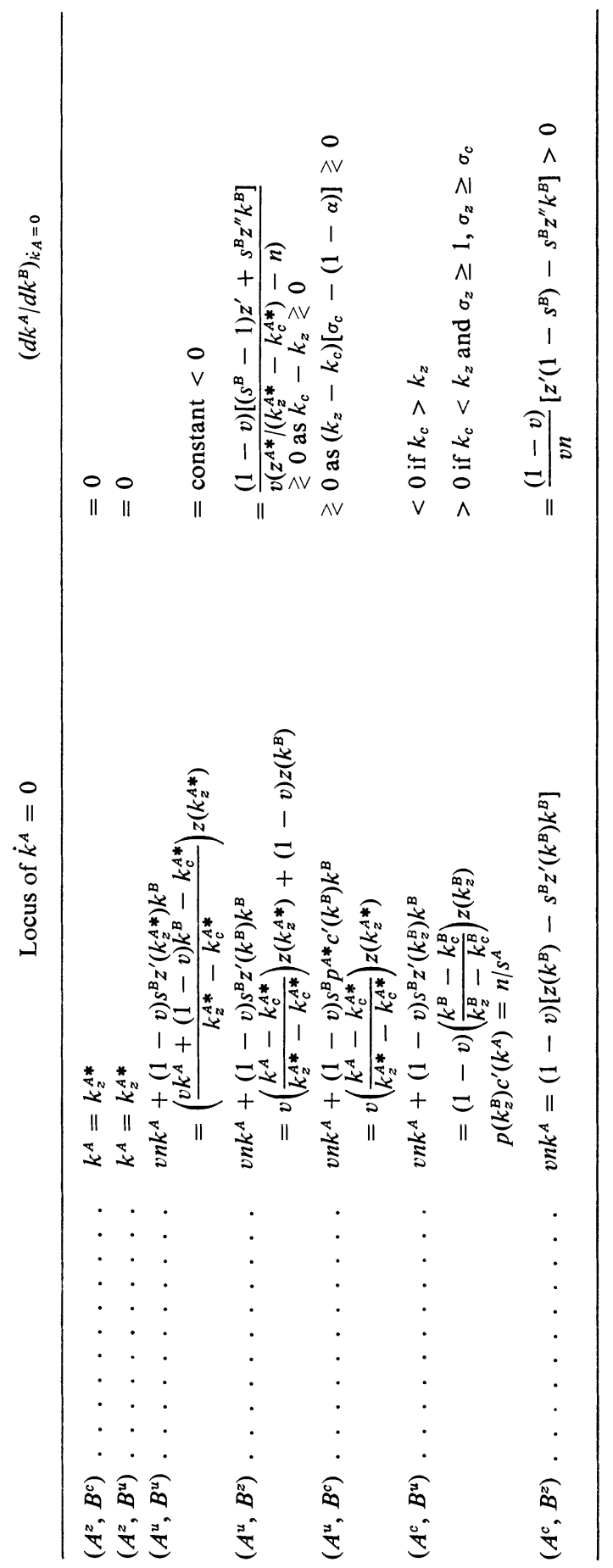




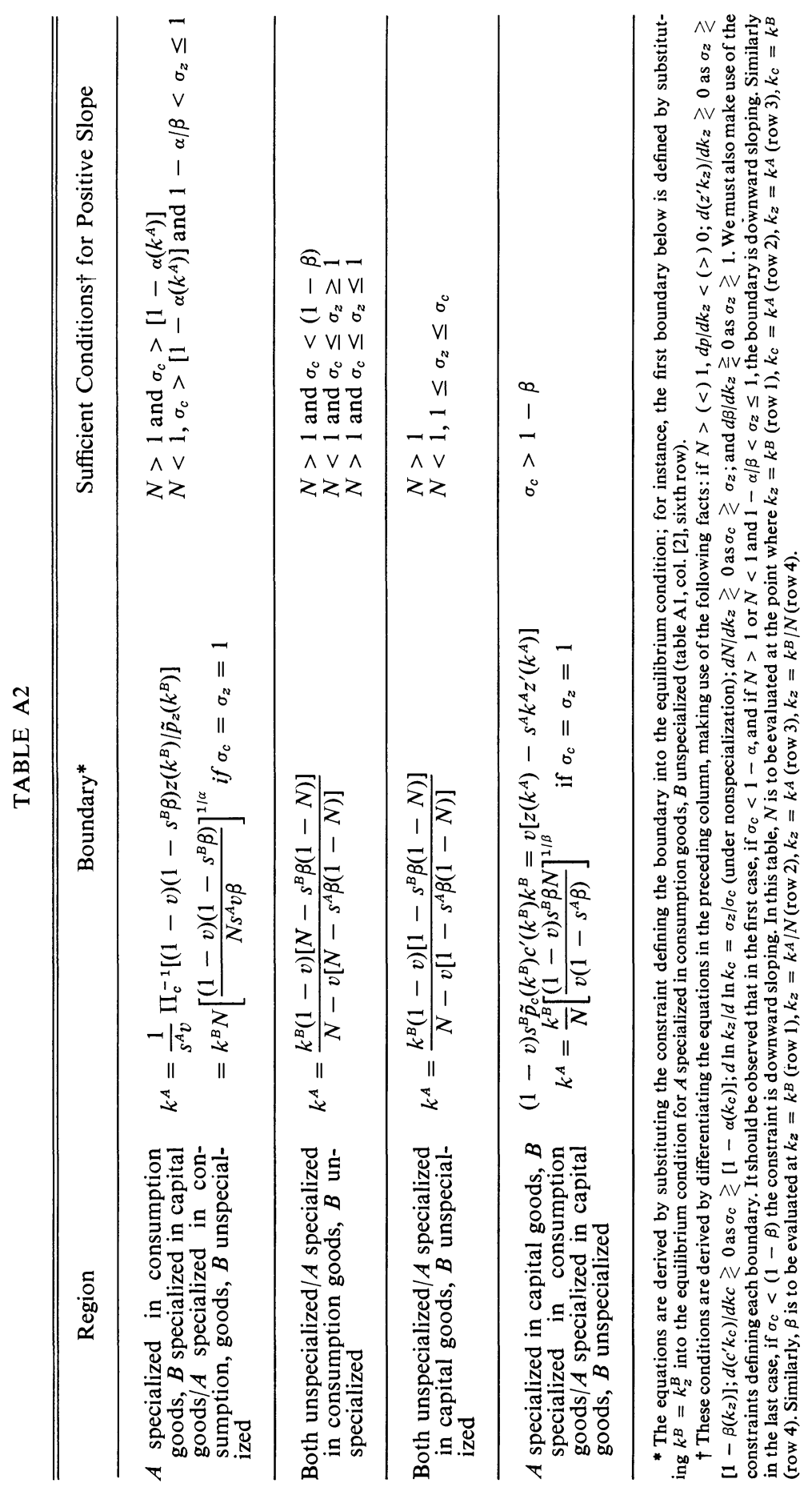



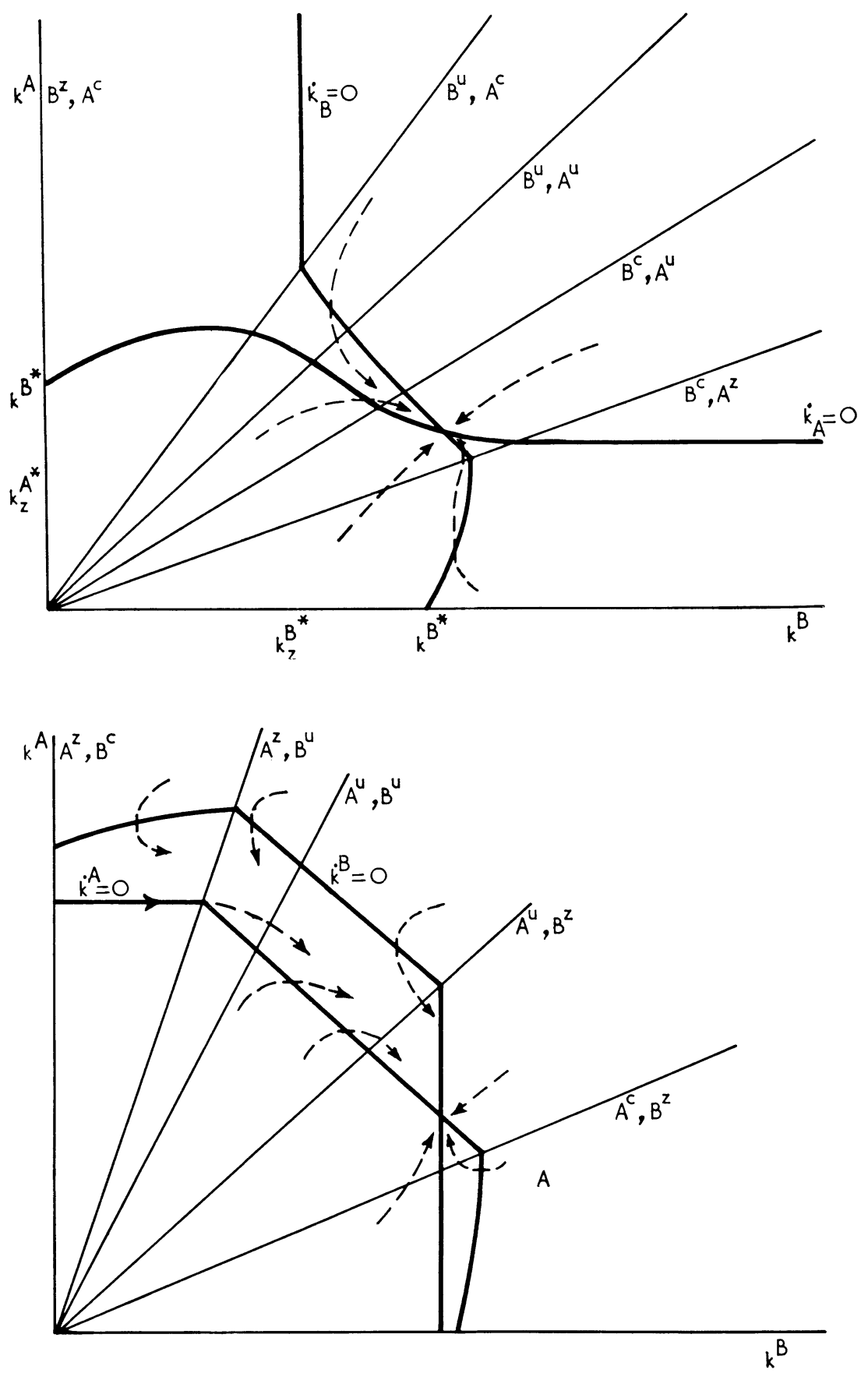

FIG. A5.-Determination of short- and long-run behavior of two-country model: Marxian savings. Top, $k_{\mathrm{c}}>k_{z} ; \sigma_{\mathrm{c}}=\sigma_{z}=1$; bottom, $k_{\mathrm{c}}<k_{z}, \sigma_{\mathrm{c}}=\sigma_{z}=1$. 


$$
k_{c}>k_{z}
$$
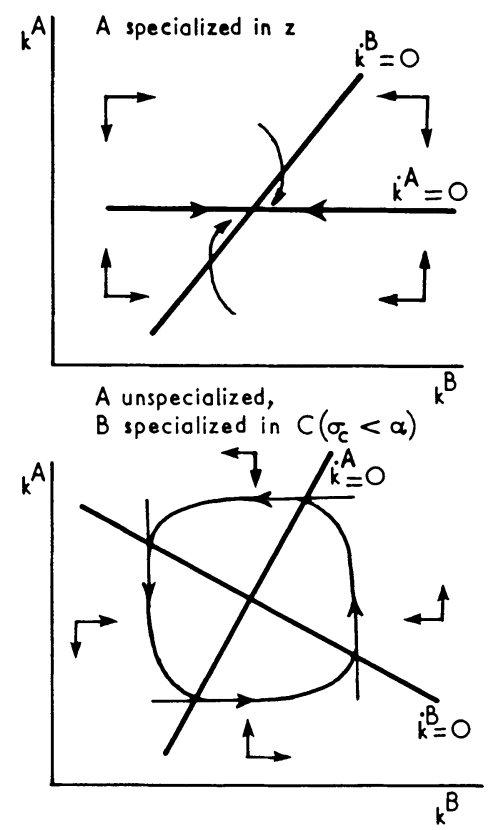

A unspecialized

$B$ specialized in $C\left(\sigma_{c}>\alpha\right)$

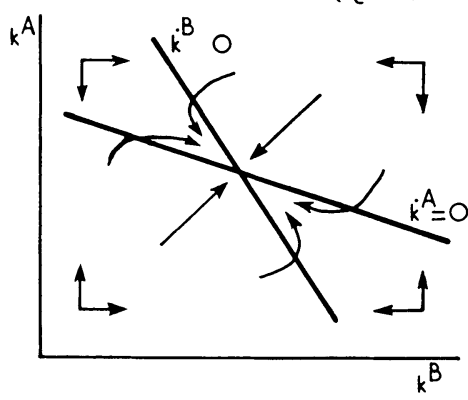

FIG. A6.-Dynamics for two-country model: Marxian savings

given in table A2. These conditions are fairly weak. For instance, if $N>1$ and $[1-\min (\alpha, \beta)]<\sigma_{c} \leq \sigma_{z} \leq 1$, then all boundaries are upward sloping.

For $\dot{k}^{A}=0, s^{A} r=n$ (eq. [7] above). The locus of such points is described in table A1, and the slope of the locus in each region is given in the final column of table A1. These results are obtained by observing that, when $A$ produces investment goods, $r=z^{\prime}\left(k_{z}^{A}\right)$, so if $\dot{k}^{A}=0, k_{z}^{A}=z^{-1}\left(n / s^{A}\right)=k_{z}^{A *}$, and if $A$ specializes in producing $z$ goods, $k^{A}=k_{z}^{A *}$. If $A$ produces only consumption goods, $p c^{\prime}\left(k^{A}\right)=r .^{32}$

${ }^{32}$ The calculations of the slopes are straightforward, with the following exception: if $B$ is unspecialized, $A$ specialized in consumption goods; we obtain the indicated result by observing that $d p / d k_{z} \lesseqgtr 0$ as $k_{c} \gtrless k_{z}$, and hence as $k^{A}$ rises, $k_{z}^{B}$ must fall, if $k_{c}>k_{z}$ (rise if $k_{c}<k_{z}$ ). 
If $k_{c}>k_{z}$ or if $\sigma_{z}$ and $\sigma_{c}$ are greater than or equal to unity, when $k^{A}$ is increased (regardless of the pattern of specialization), for given $k^{B}, k_{z}^{A}$ must increase, and hence above the $\dot{k}^{A}=0, \dot{k}^{A}<0$, below it, $\dot{k}^{B}>0{ }^{33}$ Since the $\dot{k}^{A}=0$ curve, which is defined for all values of $k^{B}\left(\right.$ at $\left.k^{B}=0, k^{A}=k^{A *}\right)$, and the $\dot{k}^{B}=0$, which is similarly defined, intersect only once, and since $v k^{A}+$ $(1-v) k^{B}$ is bounded, ${ }^{34}$ the world economy must either converge to the equilibrium or oscillate around it. The equilibrium can be shown to be locally stable under the above conditions. Some possible phase diagrams are given in figure A5, and "blow-ups" of the behavior near equilibrium are given in figure A6. Several features may be noted. Cycles are only possible if in longrun equilibrium the exporter of consumption goods is specialized. If the capital-goods exporter is specialized, in the given specialization region its approach to equilibrium is monotonic, but the consumption-goods exporter's approach may be monotonic. Globally, neither $k^{A}$ nor $k^{B}$ need change monotonically. Similarly, the relative price ratio need not change monotonically.

\section{References}

Bardhan, P. K. "Equilibrium Growth in the International Economy." Q.J.E. 79 (August 1965): 455-64.

- "On Factor Accumulation and the Pattern of International Specialization." Rev. Econ. Studies 33 (January 1966):39-44.

Beals, R., and Koopmans, T. C. "Maximizing Stationary Utility in a Constant Technology." Cowles Foundation Discussion Paper no. 229, July 1967.

Caves, R. E. Trade and Economic Structure. Cambridge, Mass.: Harvard Univ. Press, 1960.

Drandakis, E. M. "Factor Substitution in the Two-Sector Growth Model." Rev. Econ. Studies 30 (October 1963): 217-29.

Heckscher, E. "The Effect of Foreign Trade on the Distribution of Income." Ekonomisk Tidskrift 21 (1919):497-512. Reprinted in Readings in the Theory of International Trade, edited by H. S. Ellis and L. A. Metzler. New York: Unwin, 1949.

Inada, K. "Free Trade, Capital Accumulation, and Factor Price Equalization." Econ. Rec., vol. 44 (September 1968).

Johnson, H. G. International Trade and Economic Growth. London: Allen \& Unwin, 1958.

Kenen, P. "Nature, Capital, and Trade." J.P.E. 73 (October 1965):437-60.

Ohlin, B. Interregional and International Trade. Cambridge, Mass.: Harvard Univ. Press, 1933.

Oniki, H., and Uzawa, H. "Patterns of Trade and Investment in a Dynamic Model of International Trade." Rev. Econ. Studies, vol. 32 (January 1965).

Samuelson, P. "International Trade and the Equalization of Factor Prices." Econ. J. 58 (June 1948):163-84.

${ }^{33}$ The analysis proceeds as in the usual two-sector model. See n. 29 above.

${ }^{34}$ If $s^{A}=s^{B}=1, k \rightarrow \tilde{k}=z(\tilde{k}) / n$, and for $s^{A} \leq s^{B} \leq 1, k \leq \tilde{k}$. To verify local stability for the case of $\left(A^{u}, B^{c}\right)$ take a Taylor series approximation to the differential equations; $\dot{k}^{A}=a_{11} k^{A}+a_{12} k^{B}+e, \dot{k}^{B}=a_{21} k^{A}+a_{22} k^{B}+d$, with $a_{11}<0, a_{12}>$ $0, a_{21}<0, a_{22}<0$, so the characteristic equation $\lambda^{2}-\left(a_{11}+a_{22}\right) \lambda+a_{11} a_{22}-$ $a_{12} a_{21}$ has roots with negative real parts. Here and elsewhere, $A^{u}$ denotes $A$ unspecialized, $A^{c}$, specialized in producing consumption goods, $A^{z}$, specialized in producing capital goods. 
Samuelson, P. "International Factor Price Equalization Once Again.” Econ. J. 59 (June 1949):181-97.

" Prices of Factors and Goods in General Equilibrium." Rev. Econ. Studies 21 (1953-54):1-20.

- "Equalization of the Interest Rate along with the Real Wage." In Trade, Growth and the Balance of Payments, edited by R. E. Baldwin et al. Chicago: Rand McNally, 1965.

Stopler, W., and Samuelson, P. "Protection and Real Wages." Rev. Econ. Studies 9 (November 1941):58-73.

Uzawa, H. "On a Two Sector Model of Economic Growth." Rev. Econ. Studies 29 (October 1961): 40-47.

—. "Market Allocation and Optimum Growth." Australian Econ. Papers 7 (June 1968):17-27. (a)

- "Time Preference, the Consumption Function, and Optimum Asset Holdings." In Value, Capital and Growth, edited by J. W. Wolfe. Edinburgh: Edinburgh Univ. Press, 1968. (b)

Valavanis-Vail, S. "Leontief's Scarce Factor Paradox." J.P.E. 62 (December 1954): 523-28.

Vanek, J. "An Afterthought on the 'Real Cost-Opportunity Cost' Dispute and Some Aspects of General Equilibrium under Conditions of Variable Supplies." Rev. Econ. Studies 26 (June 1959):198-208.

Walsh, V. C. "Leisure and International Trade." Economica 23 (August 1956): 253-60. 